\title{
Modified block iterative procedure for solving the common solution of fixed point problems for two countable families of total quasi- $\phi$-asymptotically nonexpansive mappings with applications
}

Pongrus Phuangphoo ${ }^{1,2}$ and Poom Kumam ${ }^{1 *}$

${ }^{*}$ Correspondence:

poom.kum@kmutt.ac.th

'Department of Mathematics,

Faculty of Science, King Mongkut's University of Technology Thonburi (KMUTT), Bang Mod, Thung Kru, Bangkok, 10140, Thailand

Full list of author information is

available at the end of the article

\begin{abstract}
In this paper, we introduce a new iterative procedure which is constructed by the modified block hybrid projection method for solving a common solution of fixed point problems for two countable families of uniformly total quasi- $\phi$-asymptotically nonexpansive and uniformly Lipschitz continuous mappings. Under suitable conditions, some strong convergence theorems are established in a uniformly smooth and strictly convex Banach space with the Kadec-Klee property. Finally, we apply the problem of a strong convergence theorem concerning maximal monotone operators in Banach spaces.
\end{abstract}

MSC: $47 \mathrm{HO} 09$ 47H10; 47H20; 47J2O

Keywords: strong convergence theorem; total quasi- $\phi$-asymptotically nonexpansive mapping; fixed point problems

\section{Introduction}

Throughout this paper, we assume that $E$ is a real Banach space, $E^{*}$ is the dual space of $E$. Let $C$ be a nonempty, closed, and convex subset of $E$ and $\langle\cdot, \cdot\rangle$ be the pairing between $E$ and $E^{*}$. We denote the strong convergence and weak convergence of a sequence $\left\{x_{n}\right\}$ by $x_{n} \rightarrow x$ and $x_{n} \rightarrow x$, respectively, and $J: E \rightarrow 2^{E^{n}}$ is the normalized duality mapping defined by

$$
J x=\left\{f \in E^{*}:\langle x, f\rangle=\|x\|^{2}=\|f\|^{2}\right\}, \quad \forall x \in E .
$$

In the sequel, we use $F(T)$ to denote the set of fixed points of a mapping $T$ and use $\mathbb{R}$ and $\mathbb{R}^{+}$to denote the set of all real numbers and the set of all nonnegative real numbers, respectively.

Definition 1.1 Let E be a Banach space.

(1) $E$ is said to be strictly convex if $\frac{\|x+y\|}{2}<1$ for all $x, y \in U_{E}=\{z \in E:\|z\|=1\}$ with $x \neq y$.

(2) $E$ is said to be uniformly convex if for each $\varepsilon \in(0,2]$, there exists $\delta>0$ such that $\frac{\|x+y\|}{2} \leq 1-\delta$ for all $x, y \in U_{E}$ with $\|x-y\|>\varepsilon$.

\section{Springer}

(c) 2012 Phuangphoo and Kumam; licensee Springer. This is an Open Access article distributed under the terms of the Creative Commons Attribution License (http://creativecommons.org/licenses/by/2.0), which permits unrestricted use, distribution, and reproduction in any medium, provided the original work is properly cited. 
(3) $E$ is said to be smooth if the limit (1.2)

$$
\lim _{t \rightarrow 0} \frac{\|x+t y\|-\|x\|}{t}
$$

exists for each $x, y \in U_{E}$.

(4) $E$ is said to be uniformly smooth if the limit (1.2) is attained uniformly for all $x, y \in U_{E}$.

Remark 1.2 The basic properties below hold (see $[1,2])$.

(1) If $E$ is a real uniformly smooth Banach space, then $J$ is uniformly continuous on each bounded subset of $E$.

(2) If $E$ is a strictly convex reflexive Banach space, then $J^{-1}$ is hemicontinuous, that is, $J^{-1}$ is norm-to-weak ${ }^{*}$-continuous.

(3) If $E$ is a smooth and strictly convex reflexive Banach space, then $J$ is single-valued, one-to-one, and onto.

(4) A Banach space $E$ is uniformly smooth if and only if $E^{*}$ is uniformly convex.

(5) Each uniformly convex Banach space $E$ has the Kadec-Klee property; that is, for any sequence $\left\{x_{n}\right\} \subset E$, if $\left\{x_{n}\right\} \rightarrow x \in E$ and $\left\|x_{n}\right\| \rightarrow\|x\|$, then $x_{n} \rightarrow x$.

(6) A Banach space $E$ is strictly convex if and only if $J$ is strictly monotone; that is,

$$
\left\langle x-y, x^{*}-y^{*}\right\rangle>0, \quad \text { whenever } x, y \in E, x \neq y \text {, and } x^{*} \in J x, y^{*} \in J y \text {. }
$$

(7) Both uniformly smooth Banach spaces and uniformly convex Banach spaces are reflexive.

(8) $E^{*}$ is uniformly convex, then $J$ is uniformly norm-to-norm continuous on each bounded subset of $E$.

Let $E$ be a smooth and strictly convex reflexive Banach space, and let $C$ be a nonempty, closed, and convex subset of $E$. We assume that the Lyapunov functional $\phi: E \times E \rightarrow \mathbb{R}^{+}$ is defined by $[3,4]$

$$
\phi(x, y)=\|x\|^{2}-2\langle x, J y\rangle+\|y\|^{2}, \quad \forall x, y \in E .
$$

From the definition of $\phi$, it is easy to see that

$$
(\|x\|-\|y\|)^{2} \leq \phi(x, y) \leq(\|x\|+\|y\|)^{2}
$$

Let $C$ be a nonempty, closed, and convex subset of $E$. For each $x \in E$, the generalized projection $[3] \Pi_{C}: E \rightarrow C$ is defined by

$$
\Pi_{C}(x)=\arg \min _{y \in C} \phi(x, y) .
$$

Lemma 1.3 [3, 4] If $C$ is a nonempty, closed, and convex subset of a smooth and strictly convex reflexive real Banach space $E$, then

(1) for $x \in E$ and $u \in C$, one has

$$
u=\Pi_{C}(x) \quad \Leftrightarrow \quad\langle u-y, J x-J u\rangle \geq 0, \quad \forall y \in C .
$$


(2) $\phi\left(x, \Pi_{C}(y)\right)+\phi\left(\Pi_{C}(y), y\right) \leq \phi(x, y), \forall x \in C, y \in E$.

(3) $\phi(x, y)=0$ if and only if $x=y, \forall x, y \in C$.

Remark 1.4 If $E$ is a real Hilbert space $H$, then $\phi(x, y)=\|x-y\|^{2}$ and $\Pi_{C}=P_{C}$ (the metric projection of $H$ onto $C$ ).

Definition 1.5 Let $E$ be a smooth, strictly convex, and reflexive real Banach space, $C$ be a nonempty, closed, and convex subset of $E, T: C \rightarrow C$ be a mapping, and $\operatorname{Fix}(T)$ be the set of fixed points of $T$.

(1) A point $p \in C$ is said to be an asymptotic fixed point of $T$ if there exists a sequence $\left\{x_{n}\right\} \subset C$ such that $x_{n} \rightarrow p$ and $\left\|x_{n}-T x_{n}\right\| \rightarrow 0$. We denote the set of all asymptotic fixed points of $T$ by $\widehat{F}(T)$.

(2) A point $p \in C$ is said to be a strong asymptotic fixed point of $T$ if there exists a sequence $\left\{x_{n}\right\} \subset C$ such that $x_{n} \rightarrow p$ and $\left\|x_{n}-T x_{n}\right\| \rightarrow 0$. We denote the set of all strong asymptotic fixed points of $T$ by $\widetilde{F}(T)$.

Definition 1.6 Let $E$ be a smooth, strictly convex, and reflexive real Banach space, and let $C$ be a nonempty, closed, and convex subset of $E$.

(1) A mapping $T: C \rightarrow C$ is said to be closed if for each $\left\{x_{n}\right\} \subset C$ with $x_{n} \rightarrow x$ and $T x_{n} \rightarrow y$, then $T x=y$.

(2) A mapping $T: C \rightarrow C$ is said to be relatively nonexpansive $[5,6]$ if $\operatorname{Fix}(T) \neq \emptyset$, $\operatorname{Fix}(T)=\widehat{F}(T)$, and

$$
\phi(p, T x) \leq \phi(p, x), \quad \forall x \in C, p \in \operatorname{Fix}(T) .
$$

(3) A mapping $T: C \rightarrow C$ is said to be weak relatively nonexpansive [7] if $\operatorname{Fix}(T) \neq \emptyset$, $\operatorname{Fix}(T)=\widetilde{F}(T)$, and

$$
\phi(p, T x) \leq \phi(p, x), \quad \forall x \in C, p \in \operatorname{Fix}(T) .
$$

(4) A mapping $T: C \rightarrow C$ is said to be quasi- $\phi$-nonexpansive (relatively quasinonexpansive $)$ if $\operatorname{Fix}(T) \neq \emptyset$ and

$$
\phi(p, T x) \leq \phi(p, x), \quad \forall x \in C, p \in \operatorname{Fix}(T) .
$$

(5) A mapping $T: C \rightarrow C$ is said to be quasi- $\phi$-asymptotically nonexpansive (asymptotically relatively nonexpansive) if $\operatorname{Fix}(T) \neq \emptyset$ and there exists a sequence $\left\{k_{n}\right\} \subset[1, \infty)$ with $k_{n} \rightarrow 1$ such that

$$
\phi\left(p, T^{n} x\right) \leq k_{n} \phi(p, x), \quad \forall x \in C, p \in \operatorname{Fix}(T), \text { and } \forall n \geq 1 .
$$

(6) A mapping $T: C \rightarrow C$ is said to be total quasi- $\phi$-asymptotically nonexpansive if $\operatorname{Fix}(T) \neq \phi$ and there exists nonnegative real sequences $\left\{v_{n}\right\}$ and $\left\{\mu_{n}\right\}$ with $v_{n} \rightarrow 0$, $\mu_{n} \rightarrow 0$ (as $n \rightarrow \infty$ ), and a strictly increasing continuous function $\zeta: \mathbb{R}^{+} \rightarrow \mathbb{R}^{+}$with $\zeta(0)=0$ such that

$$
\phi\left(p, T^{n} x\right) \leq \phi(p, x)+v_{n} \zeta(\phi(p, x))+\mu_{n}, \quad \forall x \in C, p \in \operatorname{Fix}(T) \text {, and } \forall n \geq 1 .
$$


Remark 1.7 From Definition 1.6, it is easy to know that

(1) every relatively nonexpansive mapping is closed;

(2) every quasi- $\phi$-asymptotically nonexpansive mapping is a total quasi- $\phi$ asymptotically nonexpansive mapping, but the converse is not true;

(3) every quasi- $\phi$-nonexpansive mapping is a quasi- $\phi$-asymptotically nonexpansive mapping with $\left\{k_{n}=1\right\}$, but the converse is not true;

(4) every weak relatively nonexpansive mapping is a quasi- $\phi$-nonexpansive mapping because it does not require the condition $\operatorname{Fix}(T)=\widetilde{F}(T)$, but the converse is not true;

(5) every relatively nonexpansive mapping is a weak relatively nonexpansive mapping, but the converse is not true.

Regarding the iterative methods of nonlinear operator equations for relatively nonexpansive mappings, in 2005 Matsushita and Takahashi [5] and in 2008 Plubtieng and Ungchittrakool [6] proved the following result, respectively.

Theorem MT Let E be a uniformly convex and uniformly smooth Banach space, let C be a nonempty closed and convex subset of $E$. Let $T: C \rightarrow C$ be a relatively nonexpansive mapping, and let $\left\{\alpha_{n}\right\}$ be a real sequence in $[0,1)$ with $\lim _{\sup _{n \rightarrow \infty}} \alpha_{n}<1$. Let $\left\{x_{n}\right\}$ be a sequence defined by

$$
\left\{\begin{array}{l}
x_{0} \in C \quad \text { chosen arbitrarily, } \\
y_{n}=J^{-1}\left(\alpha_{n} J x_{0}+\left(1-\alpha_{n}\right) J T x_{n}\right), \\
C_{n}=\left\{z \in C: \phi\left(z, y_{n}\right) \leq \phi\left(z, x_{n}\right)\right\}, \\
Q_{n}=\left\{z \in C:\left\langle x_{n}-z, J x_{0}-J x_{n}\right\rangle \geq 0\right\}, \\
x_{n+1}=\Pi_{C_{n} \cap Q_{n}}\left(x_{0}\right), \quad \forall n \geq 0,
\end{array}\right.
$$

where $J$ is the duality mapping on E. If $\operatorname{Fix}(T) \neq \emptyset$, then the sequence $\left\{x_{n}\right\}$ converges strongly to $\Pi_{\mathrm{Fix}(T)}\left(x_{0}\right)$, where $\Pi_{\mathrm{Fix}(T)}(\cdot)$ is the generalized projection from $C$ onto $\operatorname{Fix}(T)$.

Theorem PU Let E be a uniformly convex and uniformly smooth Banach space, let $C$ be a nonempty, closed, and convex subset of $E$. Let $T, S: C \rightarrow C$ be two relatively nonexpansive mappings with $\Omega:=\operatorname{Fix}(T) \cap \operatorname{Fix}(S) \neq \emptyset$. Let $\left\{x_{n}\right\}$ be a sequence defined by

$$
\left\{\begin{array}{l}
x_{0} \in C \quad \text { chosen arbitrarily, } \\
y_{n}=J^{-1}\left(\alpha_{n} J x_{0}+\left(1-\alpha_{n}\right) J T z_{n}\right), \\
z_{n}=J^{-1}\left(\beta_{n}^{(1)} J x_{n}+\beta_{n}^{(2)} J T x_{n}+\beta_{n}^{(3)} J S x_{n}\right), \\
H_{n}=\left\{z \in C: \phi\left(z, y_{n}\right) \leq \phi\left(z, x_{n}\right)+\alpha_{n}\left(\|x\|^{2}+2\left\langle z, J x_{n}-J x_{0}\right\rangle\right)\right\}, \\
W_{n}=\left\{z \in C:\left\langle x_{n}-z, J x_{0}-J x_{n}\right\rangle \geq 0\right\}, \\
x_{n+1}=\Pi_{H_{n} \cap W_{n}}\left(x_{0}\right), \quad \forall n \geq 0,
\end{array}\right.
$$

with the following restrictions:

(1) $0<\alpha_{n}<1$ and $\limsup _{n \rightarrow \infty} \alpha_{n}<1$;

(2) $0 \leq \beta_{n}^{(1)}, \beta_{n}^{(2)}, \beta_{n}^{(3)} \leq 1, \lim _{n \rightarrow \infty} \beta_{n}^{(1)}=0$, and $\liminf _{n \rightarrow \infty} \beta_{n}^{(2)} \beta_{n}^{(3)}>0$.

Then the sequence $\left\{x_{n}\right\}$ converges strongly to $\Pi_{\Omega}\left(x_{0}\right)$, where $\Pi_{\Omega}(\cdot)$ is the generalized projection from $C$ onto $\Omega$. 
In 2010, Su et al. [7] introduced the concept of a countable family of weak relatively nonexpansive mappings and proved the following theorem which extends and improves Theorem MT and Theorem PU.

Theorem SXZ Let E be a uniformly convex and uniformly smooth real Banach space, let $C$ be a nonempty, closed, and convex subset of E. Let $\left\{T_{n}\right\}_{n=0}^{\infty},\left\{S_{n}\right\}_{n=0}^{\infty}: C \rightarrow C$ be two countable families of weak relatively nonexpansive mappings such that $\Omega:=\left(\bigcap_{n=0}^{\infty} \operatorname{Fix}\left(T_{n}\right)\right) \cap$ $\left(\bigcap_{n=0}^{\infty} \operatorname{Fix}\left(S_{n}\right)\right) \neq \emptyset$.

Let $\left\{x_{n}\right\}$ be a sequence defined by

$$
\left\{\begin{array}{l}
x_{0} \in C \quad \text { chosen arbitrarily, } \\
y_{n}=J^{-1}\left(\alpha_{n} J x_{n}+\left(1-\alpha_{n}\right) J z_{n}\right), \\
z_{n}=J^{-1}\left(\beta_{n}^{(1)} J x_{n}+\beta_{n}^{(2)} J T_{n} x_{n}+\beta_{n}^{(3)} J S_{n} x_{n}\right), \\
C_{n}=\left\{z \in C_{n-1} \cap Q_{n-1}: \phi\left(z, y_{n}\right) \leq \phi\left(z, x_{n}\right)\right\}, \\
C_{0}=\left\{z \in C: \phi\left(z, y_{0}\right) \leq \phi\left(z, x_{0}\right)\right\}, \\
Q_{n}=\left\{z \in C_{n-1} \cap Q_{n-1}:\left\langle x_{n}-z, J x_{0}-J x_{n}\right\rangle \geq 0\right\}, \\
Q_{0}=C, \\
x_{n+1}=\Pi_{C_{n} \cap Q_{n}}\left(x_{0}\right), \quad \forall n \geq 0,
\end{array}\right.
$$

with the conditions:

(1) $0 \leq \alpha_{n} \leq \alpha<1$ for some $\alpha \in(0,1)$;

(2) $\beta_{n}^{(1)}, \beta_{n}^{(2)}, \beta_{n}^{(3)} \in(0,1)$ such that $\beta_{n}^{(1)}+\beta_{n}^{(2)}+\beta_{n}^{(3)}=1$ for each $n \geq 1$;

(3) $\liminf _{n \rightarrow \infty} \beta_{n}^{(1)} \beta_{n}^{(2)}>0$ and $\liminf _{n \rightarrow \infty} \beta_{n}^{(2)} \beta_{n}^{(3)}>0$.

Then the sequence $\left\{x_{n}\right\}$ converges strongly to $\Pi_{\Omega}\left(x_{0}\right)$, where $\Pi_{\Omega}(\cdot)$ is the generalized projection from $C$ onto $\Omega$.

In 2011, Chang et al. [8] proved some approximation theorems for common fixed points of countable families of total quasi- $\phi$-asymptotically nonexpansive mappings which contain several kinds of mappings as their special cases in Banach spaces. Next, Chang et al. [9] modified the Halpern-type iteration algorithm for a total quasi- $\phi$-asymptotically nonexpansive mapping to have the strong convergence under a limit condition only in the framework of Banach spaces. Recently, Chang, Lee, and Chan [10] introduced a block hybrid projection algorithm for solving the convex feasibility problem and the generalized equilibrium problems for an infinite family of total quasi- $\phi$-asymptotically nonexpansive mappings and they proved strong convergence theorems in a uniformly smooth and strictly convex Banach space with the Kadec-Klee property.

Theorem CLCY Let E be a uniformly smooth and strictly convex Banach space with the Kadec-Klee property, let $C$ be a nonempty, closed, and convex subset of $E$, and let $\left\{T_{i}\right\}_{i=1}^{\infty}: C \rightarrow C$ be a countable family of closed, uniformly $L_{i}$-Lipschitz continuous, and uniformly total quasi- $\phi$-asymptotically nonexpansive mappings with nonnegative real sequences $\left\{v_{n}\right\},\left\{\mu_{n}\right\}$, and a strictly increasing continuous function $\zeta: \mathbb{R}^{+} \rightarrow \mathbb{R}^{+}$such that 
$\mu_{1}=0, v_{n} \rightarrow 0, \mu_{n} \rightarrow 0($ as $n \rightarrow \infty)$, and $\zeta(0)=0$. Let $\left\{x_{n}\right\}$ be a sequence generated by

$$
\left\{\begin{array}{l}
x_{0} \in C \quad \text { chosen arbitrarily, } C_{0}=C, \\
z_{n}=J^{-1}\left(\alpha_{n} J x_{n}+\left(1-\alpha_{n}\right) J z_{n}\right), \\
y_{n}=J^{-1}\left(\beta_{n, 0} J x_{n}+\sum_{i=1}^{\infty} \beta_{n, i} J T_{i}^{n} x_{n}\right), \\
C_{n+1}=\left\{v \in C_{n}: \phi\left(v, y_{n}\right) \leq \phi\left(v, x_{n}\right)+\xi_{n}\right\}, \\
x_{n+1}=\Pi_{C_{n+1}}\left(x_{0}\right), \quad \forall n \geq 0,
\end{array}\right.
$$

where $\xi_{n}=v_{n} \sup _{p \in \Omega} \zeta\left(\phi\left(p, x_{n}\right)\right)+\mu_{n}, \Pi_{C_{n+1}}$ is the generalized projection of E onto $C_{n+1}$. Let $\left\{\beta_{n, 0}\right\},\left\{\beta_{n, i}\right\}$, and $\left\{\alpha_{n}\right\}$ be sequences in $[0,1]$ satisfying the following conditions:

(1) for each $n \geq 0, \beta_{n, 0}+\sum_{i=1}^{\infty} \beta_{n, i}=1$;

(2) $\liminf _{n \rightarrow \infty} \beta_{n, 0} \beta_{n, i}>0$ for all $i \geq 1$;

(3) $0 \leq \alpha_{n} \leq \alpha<1$ for some $\alpha \in(0,1)$.

If $\Omega:=\bigcap_{i=1}^{\infty} \operatorname{Fix}\left(T_{i}\right)$ is a nonempty and bounded subset of $C$, then the sequence $\left\{x_{n}\right\}$ converges strongly to $\Pi_{\Omega}\left(x_{0}\right)$.

Theorem CLCZ Let $E$ be a uniformly smooth and strictly convex Banach space with the Kadec-Klee property, let $C$ be a nonempty, closed, and convex subset of $E$, and let $\left\{T_{m}\right\}_{m=1}^{\infty}: C \rightarrow C$ be a countable family of closed, uniformly $L_{m}$-Lipschitz continuous, and uniformly total quasi- $\phi$-asymptotically nonexpansive mappings with nonnegative real sequences $\left\{v_{n}\right\},\left\{\mu_{n}\right\}$, and a strictly increasing continuous function $\zeta: \mathbb{R}^{+} \rightarrow \mathbb{R}^{+}$such that $\mu_{1}=0, v_{n} \rightarrow 0, \mu_{n} \rightarrow 0($ as $n \rightarrow \infty)$, and $\zeta(0)=0$. Let $\left\{x_{n}\right\}$ be a sequence generated by

$$
\left\{\begin{array}{l}
x_{1} \in E \quad \text { chosen arbitrarily, } C_{1}=C \\
y_{n, m}=J^{-1}\left(\alpha_{n} J x_{1}+\left(1-\alpha_{n}\right) J T_{m}^{n} x_{n}\right), \quad m \geq 1 \\
C_{n+1}=\left\{z \in C_{n}: \sup _{m \geq 1} \phi\left(z, y_{n, m}\right) \leq \alpha_{n} \phi\left(z, x_{1}\right)+(1-\alpha) \phi\left(z, x_{n}\right)+\xi_{n}\right\} \\
x_{n+1}=\Pi_{C_{n+1}}\left(x_{1}\right), \quad \forall n \geq 1
\end{array}\right.
$$

where $\xi_{n}=v_{n} \sup _{p \in \Omega} \zeta\left(\phi\left(p, x_{n}\right)\right)+\mu_{n}$, and $\Pi_{C_{n+1}}$ is the generalized projection of $E$ onto $C_{n+1}$. If $\Omega:=\bigcap_{m=1}^{\infty} \operatorname{Fix}\left(T_{m}\right)$ is a nonempty and bounded subset of $C$, then the sequence $\left\{x_{n}\right\}$ converges strongly to $\Pi_{\Omega}\left(x_{1}\right)$.

Theorem CLC Let $E$ be a uniformly smooth and strictly convex Banach space with the Kadec-Klee property, let $C$ be a nonempty, closed, and convex subset of $E$, and let $\left\{S_{i}\right\}_{i=1}^{\infty}: C \rightarrow C$ be a countable family of closed, uniformly $L_{i}$-Lipschitz continuous, and uniformly total quasi- $\phi$-asymptotically nonexpansive mappings with nonnegative real sequences $\left\{v_{n}\right\},\left\{\mu_{n}\right\}$, and a strictly increasing continuous function $\zeta: \mathbb{R}^{+} \rightarrow \mathbb{R}^{+}$such that $\mu_{1}=0, v_{n} \rightarrow 0, \mu_{n} \rightarrow 0($ as $n \rightarrow \infty)$, and $\zeta(0)=0$. Let $B_{i}: C \rightarrow E^{*}(i=1,2,3, \ldots, N)$ be a finite family of continuous and monotone mappings. Let $\psi_{i}: C \rightarrow \mathbb{R}(i=1,2,3, \ldots, N)$ be a finite family of lower semi-continuous and convex functions, and let $F_{i}: C \times C \rightarrow \mathbb{R}$ $(i=1,2,3, \ldots, N)$ be a finite family of bifunctions satisfying the conditions (A1)-(A4). Suppose that $\Omega:=\left(\bigcap_{i=1}^{N} \mathfrak{F}_{i}\right) \cap\left(\bigcap_{i=1}^{\infty} \operatorname{Fix}\left(S_{i}\right)\right)$ is a nonempty and bounded subset of $C$, where $\mathfrak{F}_{i}$ $(i=1,2,3, \ldots, N)$ is the set of the following generalized mixed quasi-equilibrium problems:

$$
F_{i}(u, y)+\left\langle B_{i} u, y-u\right\rangle+\psi_{i}(y)-\psi_{i}(u) \geq 0, \quad \forall y \in C, i=1,2,3, \ldots, N
$$


Let $\left\{x_{n}\right\}$ be a sequence generated by

$$
\left\{\begin{array}{l}
x_{0} \in C \quad \text { chosen arbitrarily, } C_{0}=C, \\
y_{n}=J^{-1}\left(\beta_{n} J x_{n}+\left(1-\beta_{n}\right) J z_{n}\right), \\
z_{n}=J^{-1}\left(\alpha_{n, 0} J x_{n}+\sum_{i=1}^{\infty} \alpha_{n, i} J S_{i}^{n} x_{n}\right), \\
u_{n}^{(i)}=K_{f_{i}, r_{i}} K_{f_{i-1}, r_{i-1}} \cdots K_{f_{2}, r_{2}} K_{f_{1}, r_{1}} y_{n}, \quad i=1,2,3, \ldots, N, \\
C_{n+1}=\left\{v \in C_{n}: \max _{i=1,2,3, \ldots, N} \phi\left(v, u_{n}^{(i)}\right) \leq \phi\left(v, x_{n}\right)+\xi_{n}\right\}, \\
x_{n+1}=\Pi_{C_{n+1}}\left(x_{0}\right), \quad \forall n \geq 0,
\end{array}\right.
$$

where $\xi_{n}=v_{n} \sup _{p \in \Omega} \zeta\left(\phi\left(u, x_{n}\right)\right)+\mu_{n}, \forall n \geq 1, \Pi_{C_{n+1}}$ is the generalized projection of $E$ onto $C_{n+1}$. Let $\left\{\alpha_{n, i}\right\},\left\{\beta_{n}\right\}$ be sequences in $[0,1]$ satisfying the following conditions:

(1) for each $n \geq 0, \sum_{i=0}^{\infty} \alpha_{n, i}=1$;

(2) $\liminf _{n \rightarrow \infty}\left(1-\beta_{n}\right) \alpha_{n, 0} \alpha_{n, i}>0$ for all $i \geq 1$.

Then the sequence $\left\{x_{n}\right\}$ converges strongly to $\Pi_{\Omega}\left(x_{0}\right)$.

In this paper, motivated and inspired by the previously mentioned results, we introduce a new iterative procedure by the modified block hybrid projection method for solving a common solution of fixed point problems for two countable families of uniformly total quasi- $\phi$-asymptotically nonexpansive and uniformly Lipschitz continuous mappings in a uniformly smooth and strictly convex Banach space with the Kadec-Klee property. Then, we prove a strong convergence theorem of the iterative procedure generated by these conditions. The results obtained in this paper extend and improve several recent results in this area.

\section{Preliminaries}

Definition 2.1 Let $C$ be a nonempty, closed, and convex subset of a real Banach space $E$.

(1) A mapping $T: C \rightarrow C$ is said to be nonexpansive if

$$
\|T x-T y\| \leq\|x-y\|, \quad \forall x, y \in C
$$

(2) A mapping $T: C \rightarrow C$ is said to be uniformly L-Lipschitz continuous if there exists a constant $L>0$ such that

$$
\left\|T^{n} x-T^{n} y\right\| \leq L\|x-y\|, \quad \forall x, y \in C, \forall n \geq 1
$$

Definition 2.2 [11] Let $C$ be a nonempty, closed, and convex subset of a real Banach space $E$.

(1) A countable family of mappings $\left\{T_{i}\right\}_{i=1}^{\infty}$ is said to be a uniformly quasi- $\phi$ asymptotically nonexpansive mapping if $\bigcap_{i=1}^{\infty} \operatorname{Fix}\left(T_{i}\right) \neq \emptyset$ and there exists a sequence $\left\{k_{n}\right\} \subset[1, \infty)$ with $k_{n} \rightarrow 1$ such that for each $i \geq 1$,

$$
\phi\left(p, T_{i}^{n} x\right) \leq k_{n} \phi(p, x), \quad \forall x \in C, p \in \bigcap_{i=1}^{\infty} \operatorname{Fix}\left(T_{i}\right), \text { and } \forall n \geq 1
$$

(2) A countable family of mappings $\left\{T_{i}\right\}_{i=1}^{\infty}$ is said to be a uniformly total quasi- $\phi$ asymptotically nonexpansive mapping if $\bigcap_{i=1}^{\infty} \operatorname{Fix}\left(T_{i}\right) \neq \emptyset$ and there exist 
nonnegative real sequences $\left\{v_{n}\right\}$ and $\left\{\mu_{n}\right\}$ with $v_{n} \rightarrow 0, \mu_{n} \rightarrow 0($ as $n \rightarrow \infty)$, and a strictly increasing continuous function $\zeta: \mathbb{R}^{+} \rightarrow \mathbb{R}^{+}$with $\zeta(0)=0$ such that for each $i \geq 1$,

$$
\phi\left(p, T_{i}^{n} x\right) \leq \phi(p, x)+v_{n} \zeta(\phi(p, x))+\mu_{n}, \quad \forall x \in C, p \in \bigcap_{i=1}^{\infty} \operatorname{Fix}\left(T_{i}\right) \text {, and } \forall n \geq 1 .
$$

Lemma 2.3 [4] Let E be a uniformly smooth and strictly convex real Banach space, and let $\left\{x_{n}\right\}$ and $\left\{y_{n}\right\}$ be two sequences of $E$. If $\phi\left(x_{n}, y_{n}\right) \rightarrow 0$ and either $\left\{x_{n}\right\}$ or $\left\{y_{n}\right\}$ is bounded, then $\left\|x_{n}-y_{n}\right\| \rightarrow 0$.

Lemma 2.4 [8] Let E be a uniformly smooth and strictly convex real Banach space with the Kadec-Klee property, and let $C$ be a nonempty, closed, and convex subset of E. Let $\left\{x_{n}\right\}$ and $\left\{y_{n}\right\}$ be two sequences in $C$ and $p \in E$. If $x_{n} \rightarrow p$ and $\phi\left(x_{n}, y_{n}\right) \rightarrow 0$, then $y_{n} \rightarrow p$.

Lemma 2.5 [8] Let E be a uniformly smooth and strictly convex real Banach space with the Kadec-Klee property, and let $C$ be a nonempty, closed, and convex subset of E. Let $T: C \rightarrow C$ be a closed and total quasi- $\phi$-asymptotically nonexpansive mapping with nonnegative real sequences $\left\{v_{n}\right\},\left\{\mu_{n}\right\}$, and a strictly increasing continuous function $\zeta: \mathbb{R}^{+} \rightarrow \mathbb{R}^{+}$such that $v_{n} \rightarrow 0, \mu_{n} \rightarrow 0($ as $n \rightarrow \infty)$, and $\zeta(0)=0$. If $\mu_{1}=0$, then the fixed point set $\operatorname{Fix}(T)$ is a closed and convex subset of $C$.

Lemma 2.6 [11] Let E be a uniformly convex Banach space, $r>0$ be a positive number, and $B_{r}(0)$ be a closed ball of $E$. Then for any given sequence $\left\{x_{n}\right\}_{n=1}^{\infty} \subset B_{r}(0)$ and for any given $\left\{\lambda_{n}\right\}_{n=1}^{\infty} \subset(0,1)$ with $\sum_{n=1}^{\infty} \lambda_{n}=1$, there exists a continuous, strictly increasing, and convex function $g:[0,2 r) \rightarrow[0, \infty)$ with $g(0)=0$ such that for any positive integers $i, j$ with $i<j$,

$$
\left\|\sum_{n=1}^{\infty} \lambda_{n} x_{n}\right\|^{2} \leq \sum_{n=1}^{\infty} \lambda_{n}\left\|x_{n}\right\|^{2}-\lambda_{i} \lambda_{j} g\left(\left\|x_{i}-x_{j}\right\|\right) .
$$

\section{Main results}

In this section, we shall use the modified block hybrid projection method to study a common solution of fixed point problems for two countable families of closed and $L_{i}, \ell_{i}$ Lipschitz continuous and uniformly total quasi- $\phi$-asymptotically nonexpansive mappings in Banach spaces. For the purpose, we assume the following hypotheses.

(A1) Let $\left\{T_{i}\right\}_{i=1}^{\infty}: C \rightarrow C$ be a countable family of closed, uniformly $L_{i}$-Lipschitz continuous, and uniformly total quasi- $\phi$-asymptotically nonexpansive mappings with nonnegative real sequences $\left\{v_{n}\right\},\left\{\mu_{n}\right\}$ and a strictly increasing function $\zeta: \mathbb{R}^{+} \rightarrow \mathbb{R}^{+}$such that $v_{n} \rightarrow 0, \mu_{n} \rightarrow 0($ as $n \rightarrow \infty), \mu_{1}=0$, and $\zeta(0)=0$, and for each $i \geq 1$,

$$
\phi\left(p, T_{i}^{n} x\right) \leq \phi(p, x)+v_{n} \zeta(\phi(p, x))+\mu_{n}, \quad \forall x \in C, p \in \bigcap_{i=1}^{\infty} \operatorname{Fix}\left(T_{i}\right), \text { and } \forall n \geq 1 .
$$

(A2) Let $\left\{S_{i}\right\}_{i=1}^{\infty}: C \rightarrow C$ be a countable family of closed, uniformly $\ell_{i}$-Lipschitz continuous, and uniformly total quasi- $\phi$-asymptotically nonexpansive mappings with nonnegative real sequences $\left\{\kappa_{n}\right\},\left\{\omega_{n}\right\}$ and a strictly increasing function $\rho: \mathbb{R}^{+} \rightarrow \mathbb{R}^{+}$such that 


$$
\begin{aligned}
\kappa_{n} \rightarrow 0, \omega_{n} \rightarrow 0 & (\text { as } n \rightarrow \infty), \omega_{1}=0, \text { and } \rho(0)=0, \text { and for each } i \geq 1, \\
& \phi\left(p, S_{i}^{n} x\right) \leq \phi(p, x)+\kappa_{n} \rho(\phi(p, x))+\omega_{n}, \quad \forall x \in C, p \in \bigcap_{i=1}^{\infty} \operatorname{Fix}\left(S_{i}\right), \text { and } \forall n \geq 1 .
\end{aligned}
$$

Theorem 3.1 Let E be a uniformly smooth and strictly convex real Banach space with the Kadec-Klee property, let $C$ be a nonempty, closed, and convex subset of $E$, and let $\left\{T_{i}\right\}_{i=1}^{\infty}$ and $\left\{S_{i}\right\}_{i=1}^{\infty}$ satisfy the above conditions (A1)-(A2), respectively.

Suppose that $\Omega:=\left(\bigcap_{i=1}^{\infty} \operatorname{Fix}\left(T_{i}\right)\right) \cap\left(\bigcap_{i=1}^{\infty} \operatorname{Fix}\left(S_{i}\right)\right)$ is nonempty and bounded in $C$. Let $\left\{x_{n}\right\}_{n=1}^{\infty},\left\{y_{n}\right\}_{n=1}^{\infty}$, and $\left\{z_{n}\right\}_{n=1}^{\infty}$ be sequences generated by

$$
\left\{\begin{array}{l}
x_{0} \in C \quad \text { chosen arbitrarily, } C_{0}=C, \\
z_{n}=J^{-1}\left(\alpha_{n, 0} J x_{n}+\sum_{i=1}^{\infty} \alpha_{n, i} J S_{i}^{n} y_{n}\right), \\
y_{n}=J^{-1}\left(\beta_{n, 0} J x_{n}+\sum_{i=1}^{\infty} \beta_{n, i} J T_{i}^{n} x_{n}\right), \\
C_{n+1}=\left\{v \in C_{n}: \phi\left(v, y_{n}\right) \leq \phi\left(v, x_{n}\right)+\xi_{n} \text { and } \phi\left(v, z_{n}\right) \leq \phi\left(v, x_{n}\right)+\theta_{n}\right\}, \\
x_{n+1}=\Pi_{C_{n+1}}\left(x_{0}\right), \quad \forall n \geq 0,
\end{array}\right.
$$

where $\xi_{n}=v_{n} \sup _{p \in \Omega} \zeta\left(\phi\left(p, x_{n}\right)\right)+\mu_{n}$ and $\theta_{n}=\kappa_{n} \sup _{p \in \Omega} \rho\left(\phi\left(p, x_{n}\right)\right)+\omega_{n}$.

Let $\left\{\alpha_{n, i}\right\}$ and $\left\{\beta_{n, i}\right\}$ be coefficient sequences in $[0,1]$ satisfying the following conditions:

(1) $\sum_{i=0}^{\infty} \alpha_{n, i}=1$ and $\sum_{i=0}^{\infty} \beta_{n, i}=1$;

(2) $\liminf _{n \rightarrow \infty} \alpha_{n, 0} \alpha_{n, i}>0$, and $\liminf _{n \rightarrow \infty} \beta_{n, 0} \beta_{n, i}>0, \forall i \geq 1$.

Then the sequence $\left\{x_{n}\right\}_{n=1}^{\infty}$ converges strongly to some point $p^{*}$, where $p^{*}=\Pi_{\Omega}\left(x_{0}\right)$.

Proof We shall complete this proof of Theorem 3.1 in seven steps.

Step 1 . We will show that $\Omega$ and $C_{n+1}$ are closed and convex for each $n \geq 0$.

In fact, it follows from Lemma 2.5 that $\operatorname{Fix}\left(T_{i}\right)$ and $\operatorname{Fix}\left(S_{i}\right)$, for any $i \geq 1$, are closed and convex subsets of $C$. Therefore, $\Omega$ is closed and convex in $C$.

Clearly, $C_{0}=C$ is closed and convex. Suppose that $C_{n}$ is closed and convex for some $n \geq 1$.

By the assumption of $C_{n+1}$,

$$
\phi\left(v, y_{n}\right) \leq \phi\left(v, x_{n}\right)+\xi_{n}
$$

is equivalent to

$$
\|v\|^{2}-2\left\langle v, J y_{n}\right\rangle+\left\|y_{n}\right\|^{2} \leq\|v\|^{2}-2\left\langle v, J x_{n}\right\rangle+\left\|x_{n}\right\|^{2}+\xi_{n} .
$$

So that $2\left\langle v, J x_{n}\right\rangle-2\left\langle v, J y_{n}\right\rangle=2\left\langle v, J x_{n}-J y_{n}\right\rangle \leq\left\|x_{n}\right\|^{2}-\left\|y_{n}\right\|^{2}+\xi_{n}$.

Again, by the assumption of $C_{n+1}$,

$$
\phi\left(v, z_{n}\right) \leq \phi\left(v, x_{n}\right)+\theta_{n}
$$

is equivalent to

$$
\|v\|^{2}-2\left\langle v, J z_{n}\right\rangle+\left\|z_{n}\right\|^{2} \leq\|v\|^{2}-2\left\langle v, J x_{n}\right\rangle+\left\|x_{n}\right\|^{2}+\theta_{n} .
$$

So that $2\left\langle v, J x_{n}\right\rangle-2\left\langle v, J z_{n}\right\rangle=2\left\langle v, J x_{n}-J z_{n}\right\rangle \leq\left\|x_{n}\right\|^{2}-\left\|z_{n}\right\|^{2}+\theta_{n}$. 
Hence, $C_{n+1}=\left\{v \in C_{n}: 2\left\langle v, J x_{n}-J y_{n}\right\rangle \leq\left\|x_{n}\right\|^{2}-\left\|y_{n}\right\|^{2}+\xi_{n}\right.$ and $2\left\langle v, J x_{n}-J z_{n}\right\rangle \leq\left\|x_{n}\right\|^{2}-$ $\left.\left\|z_{n}\right\|^{2}+\theta_{n}\right\}$ is closed and convex.

Step 2. We will show that $\left\{x_{n}\right\}$ is bounded and $\left\{\phi\left(x_{n}, x_{0}\right)\right\}$ is a convergent sequence for all $n \geq 1$.

Indeed, it follows from (3.1) and Lemma 1.3(2) that

$$
\begin{aligned}
\phi\left(x_{n}, x_{0}\right) & =\phi\left(\Pi_{C_{n}}\left(x_{0}\right), x_{0}\right) \\
& \leq \phi\left(p, x_{0}\right)-\phi\left(p, \Pi_{C_{n}}\left(x_{0}\right)\right) \\
& \leq \phi\left(p, x_{0}\right), \quad \forall n \geq 0, p \in \Omega .
\end{aligned}
$$

This implies that $\left\{\phi\left(x_{n}, x_{0}\right)\right\}$ is bounded. By virtue of (1.3), the sequence $\left\{x_{n}\right\}$ is also bounded.

By the assumption of $C_{n}$, we have $C_{n+1} \subset C_{n}, x_{n}=\Pi_{C_{n}}\left(x_{0}\right)$ and $x_{n+1}=\Pi_{C_{n+1}}\left(x_{0}\right)$.

This implies that $x_{n+1} \in C_{n+1} \subset C_{n}$ and

$$
\phi\left(x_{n}, x_{0}\right) \leq \phi\left(x_{n+1}, x_{0}\right), \quad \forall n \geq 0 .
$$

Therefore, $\left\{\phi\left(x_{n}, x_{0}\right)\right\}$ is a convergent sequence. Without loss of generality, we can assume that

$$
\lim _{n \rightarrow \infty} \phi\left(x_{n}, x_{0}\right)=d \geq 0
$$

Step 3. We will show that $\Omega \subset C_{n}$ for all $n \geq 0$.

It is obvious that $\Omega \subset C_{0}=C$. Suppose that $\Omega \subset C_{n}$ for some $n \geq 1$. For any given $p \in \Omega$, from (3.1) and Lemma 2.6, we compute

$$
\begin{aligned}
& \phi\left(p, y_{n}\right)=\phi\left(p, J^{-1}\left(\beta_{n, 0} J x_{n}+\sum_{i=1}^{\infty} \beta_{n, i} J T_{i}^{n} x_{n}\right)\right) \\
& =\|p\|^{2}-2\left\langle p, \beta_{n, 0} J x_{n}+\sum_{i=1}^{\infty} \beta_{n, i} J T_{i}^{n} x_{n}\right\rangle+\left\|\beta_{n, 0} J x_{n}+\sum_{i=1}^{\infty} \beta_{n, i} J T_{i}^{n} x_{n}\right\|^{2} \\
& \leq\|p\|^{2}-2 \beta_{n, 0}\left\langle p, J x_{n}\right\rangle-2 \sum_{i=1}^{\infty} \beta_{n, i}\left\langle p, J T_{i}^{n} x_{n}\right\rangle \\
& +\beta_{n, 0}\left\|x_{n}\right\|^{2}+\sum_{i=1}^{\infty} \beta_{n, i}\left\|T_{i}^{n} x_{n}\right\|^{2} \\
& -\beta_{n, 0} \beta_{n, i} g\left(\left\|J x_{n}-J T_{i}^{n} x_{n}\right\|\right) \\
& =\beta_{n, 0} \phi\left(p, x_{n}\right)+\left(1-\beta_{n, 0}\right)\|p\|^{2} \\
& -2 \sum_{i=1}^{\infty} \beta_{n, i}\left|p, J T_{i}^{n} x_{n}\right\rangle+\sum_{i=1}^{\infty} \beta_{n, i}\left\|T_{i}^{n} x_{n}\right\|^{2} \\
& -\beta_{n, 0} \beta_{n, i} g\left(\left\|J x_{n}-J T_{i}^{n} x_{n}\right\|\right) \\
& =\beta_{n, 0} \phi\left(p, x_{n}\right)+\sum_{i=1}^{\infty} \beta_{n, i} \phi\left(p, T_{i}^{n} x_{n}\right)-\beta_{n, 0} \beta_{n, i} g\left(\left\|J x_{n}-J T_{i}^{n} x_{n}\right\|\right)
\end{aligned}
$$




$$
\begin{aligned}
\leq & \beta_{n, 0} \phi\left(p, x_{n}\right)+\sum_{i=1}^{\infty} \beta_{n, i}\left[\phi\left(p, x_{n}\right)+v_{n} \zeta\left(\phi\left(p, x_{n}\right)\right)+\mu_{n}\right] \\
& -\beta_{n, 0} \beta_{n, i} g\left(\left\|J x_{n}-J T_{i}^{n} x_{n}\right\|\right) \\
= & \left(\beta_{n, 0}+\sum_{i=1}^{\infty} \beta_{n, i}\right) \phi\left(p, x_{n}\right)+\sum_{i=1}^{\infty} \beta_{n, i}\left[v_{n} \zeta\left(\phi\left(p, x_{n}\right)\right)+\mu_{n}\right] \\
& -\beta_{n, 0} \beta_{n, i} g\left(\left\|J x_{n}-J T_{i}^{n} x_{n}\right\|\right) \\
\leq & \phi\left(p, x_{n}\right)+v_{n} \zeta\left(\phi\left(p, x_{n}\right)\right)+\mu_{n}-\beta_{n, 0} \beta_{n, i} g\left(\left\|J x_{n}-J T_{i}^{n} x_{n}\right\|\right) \\
\leq & \phi\left(p, x_{n}\right)+v_{n} \sup _{p \in \Omega} \zeta\left(\phi\left(p, x_{n}\right)\right)+\mu_{n}-\beta_{n, 0} \beta_{n, i} g\left(\left\|J x_{n}-J T_{i}^{n} x_{n}\right\|\right) \\
= & \phi\left(p, x_{n}\right)+\xi_{n}-\beta_{n, 0} \beta_{n, i} g\left(\left\|J x_{n}-J T_{i}^{n} x_{n}\right\|\right) .
\end{aligned}
$$

It follows that

$$
\phi\left(p, y_{n}\right) \leq \phi\left(p, x_{n}\right)+\xi_{n}, \quad \text { where } \xi_{n}=v_{n} \sup _{p \in \Omega} \zeta\left(\phi\left(p, x_{n}\right)\right)+\mu_{n} .
$$

From (3.1) and Lemma 2.6, we compute

$$
\begin{aligned}
\phi\left(p, z_{n}\right)= & \phi\left(p, J^{-1}\left(\alpha_{n, 0} J x_{n}+\sum_{i=1}^{\infty} \alpha_{n, i} J S_{i}^{n} y_{n}\right)\right) \\
= & \|p\|^{2}-2\left\langle p, \alpha_{n, 0} J x_{n}+\sum_{i=1}^{\infty} \alpha_{n, i} J S_{i}^{n} y_{n}\right\rangle+\left\|\alpha_{n, 0} J x_{n}+\sum_{i=1}^{\infty} \alpha_{n, i} J S_{i}^{n} y_{n}\right\|^{2} \\
\leq & \|p\|^{2}-2 \alpha_{n, 0}\left\langle p, J x_{n}\right\rangle-2 \sum_{i=1}^{\infty} \alpha_{n, i}\left\langle p, J S_{i}^{n} y_{n}\right\rangle+\alpha_{n, 0}\left\|x_{n}\right\|^{2}+\sum_{i=1}^{\infty} \alpha_{n, i}\left\|S_{i}^{n} y_{n}\right\|^{2} \\
& -\alpha_{n, 0} \alpha_{n, i} g\left(\left\|J y_{n}-J S_{i}^{n} y_{n}\right\|\right) \\
= & \alpha_{n, 0} \phi\left(p, x_{n}\right)+\left(1-\alpha_{n, 0}\right)\|p\|^{2}-2 \sum_{i=1}^{\infty} \alpha_{n, i}\left\langle p, J S_{i}^{n} y_{n}\right\rangle+\sum_{i=1}^{\infty} \alpha_{n, i}\left\|S_{i}^{n} y_{n}\right\|^{2} \\
& -\alpha_{n, 0} \alpha_{n, i} g\left(\left\|J y_{n}-J S_{i}^{n} y_{n}\right\|\right) \\
= & \alpha_{n, 0} \phi\left(p, x_{n}\right)+\sum_{i=1}^{\infty} \alpha_{n, i} \phi\left(p, S_{i}^{n} y_{n}\right)-\alpha_{n, 0} \alpha_{n, i} g\left(\left\|J y_{n}-J S_{i}^{n} y_{n}\right\|\right) \\
\leq & \alpha_{n, 0} \phi\left(p, x_{n}\right)+\sum_{i=1}^{\infty} \alpha_{n, i}\left[\phi(p, x)+\kappa_{n} \rho(\phi(p, x))+\omega_{n}\right] \\
& -\alpha_{n, 0} \alpha_{n, i} g\left(\left\|J y_{n}-J S_{i}^{n} y_{n}\right\|\right) \\
= & \left(\alpha_{n, 0}+\sum_{i=1}^{\infty} \alpha_{n, i}\right) \phi\left(p, x_{n}\right)+\sum_{i=1}^{\infty} \alpha_{n, i}\left[\kappa_{n} \rho(\phi(p, x))+\omega_{n}\right] \\
& -\alpha_{n, 0} \alpha_{n, i} g\left(\left\|J y_{n}-J S_{i}^{n} y_{n}\right\|\right) \\
\leq & \phi\left(p, x_{n}\right)+\kappa_{n} \rho(\phi(p, x))+\omega_{n}-\alpha_{n, 0} \alpha_{n, i} g\left(\left\|J y_{n}-J S_{i}^{n} y_{n}\right\|\right) \\
\leq & \phi\left(p, x_{n}\right)+\kappa_{n} \sup _{p \in \Omega} \rho(\phi(p, x))+\omega_{n}-\alpha_{n, 0} \alpha_{n, i} g\left(\left\|J y_{n}-J S_{i}^{n} y_{n}\right\|\right) \\
= & \phi\left(p, x_{n}\right)+\theta_{n}-\alpha_{n, 0} \alpha_{n, i} g\left(\left\|J y_{n}-J S_{i}^{n} y_{n}\right\|\right) . \\
& \\
&
\end{aligned}
$$


It follows that

$$
\phi\left(p, z_{n}\right) \leq \phi\left(p, x_{n}\right)+\theta_{n}, \quad \text { where } \theta_{n}=\kappa_{n} \sup _{p \in \Omega} \rho(\phi(p, x))+\omega_{n} .
$$

By the assumptions of $\left\{v_{n}\right\},\left\{\mu_{n}\right\},\left\{\kappa_{n}\right\}$, and $\left\{\omega_{n}\right\}$, and from (3.3) and (3.5), we obtain

$$
\xi_{n}=v_{n} \sup _{p \in \Omega} \zeta\left(\phi\left(p, x_{n}\right)\right)+\mu_{n} \rightarrow 0 \quad(\text { as } n \rightarrow \infty)
$$

and

$$
\theta_{n}=\kappa_{n} \sup _{p \in \Omega} \rho\left(\phi\left(p, x_{n}\right)\right)+\omega_{n} \rightarrow 0 \quad(\text { as } n \rightarrow \infty) .
$$

So, we get $p \in C_{n+1}$. This implies that $\Omega \subset C_{n}$ for all $n \geq 0$, and the sequence $\left\{x_{n}\right\}$ is well defined.

Step 4. We will show that there exists some point $p^{*} \in C$ such that $x_{n} \rightarrow p^{*}$.

In fact, since $\left\{x_{n}\right\}$ is bounded and $E$ is reflexive, then there exists a subsequence $\left\{x_{n_{i}}\right\} \subset$ $\left\{x_{n}\right\}$ such that $x_{n_{i}} \rightarrow p^{*}$ (some point in $C$ ).

Since $C_{n}$ is closed and convex and $C_{n+1} \subset C_{n}$, it follows that $C_{n}$ is weakly closed and $p^{*} \in C_{n}$ for each $n \geq 0$.

In view of $x_{n_{i}}=\Pi_{C_{n_{i}}}\left(x_{0}\right)$, we have

$$
\phi\left(x_{n_{i}}, x_{0}\right) \leq \phi\left(p^{*}, x_{0}\right), \quad \forall n_{i} \geq 0
$$

Since the norm $\|\cdot\|$ is weakly lower semi-continuous, we have

$$
\begin{aligned}
\liminf _{n_{i} \rightarrow \infty} \phi\left(x_{n_{i}}, x_{0}\right) & =\liminf _{n_{i} \rightarrow \infty}\left\{\left\|x_{n_{i}}\right\|^{2}-2\left\langle x_{n_{i}}, J x_{0}\right\rangle+\left\|x_{0}\right\|^{2}\right\} \\
& \geq\left\|p^{*}\right\|^{2}-2\left\langle p^{*}, J x_{0}\right\rangle+\left\|x_{0}\right\|^{2}=\phi\left(p^{*}, x_{0}\right),
\end{aligned}
$$

and so

$$
\phi\left(p^{*}, x_{0}\right) \leq \liminf _{n_{i} \rightarrow \infty} \phi\left(x_{n_{i}}, x_{0}\right) \leq \limsup _{n_{i} \rightarrow \infty} \phi\left(x_{n_{i}}, x_{0}\right) \leq \phi\left(p^{*}, x_{0}\right) .
$$

This implies that $\lim _{n_{i} \rightarrow \infty} \phi\left(x_{n_{i}}, x_{0}\right)=\phi\left(p^{*}, x_{0}\right)$, and so $\left\|x_{n_{i}}\right\| \rightarrow\left\|p^{*}\right\|$. Since $x_{n_{i}} \rightarrow p^{*}$, and by virtue of the Kadec-Klee property of $E$, we obtain

$$
\lim _{n_{i} \rightarrow \infty} x_{n_{i}}=p^{*}, \quad \text { as } n_{i} \rightarrow \infty
$$

The sequence $\left\{\phi\left(x_{n}, x_{0}\right)\right\}$ is convergent, and $\lim _{n_{i} \rightarrow \infty} \phi\left(x_{n_{i}}, x_{0}\right)=\phi\left(p^{*}, x_{0}\right)$, which implies that $\lim _{n \rightarrow \infty} \phi\left(x_{n}, x_{0}\right)=\phi\left(p^{*}, x_{0}\right)$. If there exists some subsequence $\left\{x_{n_{j}}\right\} \subset\left\{x_{n}\right\}$ such that $x_{n_{j}} \rightarrow q$, then from Lemma 1.3(2) we have

$$
\begin{aligned}
\phi\left(p^{*}, q\right) & =\lim _{n_{i}, n_{j} \rightarrow \infty} \phi\left(x_{n_{i}}, x_{n_{j}}\right) \\
& =\lim _{n_{i}, n_{j} \rightarrow \infty} \phi\left(x_{n_{i}}, \Pi_{C_{n_{j}}}\left(x_{0}\right)\right)
\end{aligned}
$$




$$
\begin{aligned}
& \leq \lim _{n_{i}, n_{j} \rightarrow \infty}\left[\phi\left(x_{n_{i}}, x_{0}\right)-\phi\left(\Pi_{C_{n_{j}}}\left(x_{0}\right), x_{0}\right)\right] \\
& =\lim _{n_{i}, n_{j} \rightarrow \infty}\left[\phi\left(x_{n_{i}}, x_{0}\right)-\phi\left(x_{n_{j}}, x_{0}\right)\right] \\
& =\phi\left(p^{*}, x_{0}\right)-\phi\left(p^{*}, x_{0}\right)=0 .
\end{aligned}
$$

This implies that $p^{*}=q$, and so

$$
\lim _{n \rightarrow \infty} x_{n}=p^{*}
$$

Step 5. We will show that $\lim _{n \rightarrow \infty}\left\|J x_{n}-J y_{n}\right\|=0$ and $\lim _{n \rightarrow \infty}\left\|J x_{n}-J z_{n}\right\|=0$ as $n \rightarrow \infty$. Since $x_{n+1} \in C_{n+1} \subset C_{n}$, by the definition of $C_{n+1}$, we have

$$
\begin{aligned}
\phi\left(x_{n+1}, x_{n}\right) & =\phi\left(x_{n+1}, \Pi_{C_{n}}\left(x_{0}\right)\right) \\
& \leq \phi\left(x_{n+1}, x_{0}\right)-\phi\left(\Pi_{C_{n}}\left(x_{0}\right), x_{0}\right) \\
& =\phi\left(x_{n+1}, x_{0}\right)-\phi\left(x_{n}, x_{0}\right) .
\end{aligned}
$$

Since $\lim _{n \rightarrow \infty} \phi\left(x_{n}, x_{0}\right)$ exists, and we are taking $n \rightarrow \infty$ in (3.10), then $\phi\left(x_{n+1}, x_{n}\right) \rightarrow 0$. It follows from Lemma 2.3 that

$$
\lim _{n \rightarrow \infty}\left\|x_{n+1}-x_{n}\right\|=0
$$

By the definition of $C_{n+1}$ and $x_{n+1} \in C_{n+1}$, we get

$$
\begin{aligned}
& \phi\left(x_{n+1}, y_{n}\right) \leq \phi\left(x_{n+1}, x_{n}\right)+\xi_{n}, \quad \text { and } \\
& \phi\left(x_{n+1}, z_{n}\right) \leq \phi\left(x_{n+1}, x_{n}\right)+\theta_{n} .
\end{aligned}
$$

From $\phi\left(x_{n+1}, x_{n}\right) \rightarrow 0, \xi_{n} \rightarrow 0$, and $\theta_{n} \rightarrow 0$, as $n \rightarrow \infty$, we obtain

$$
\phi\left(x_{n+1}, y_{n}\right) \rightarrow 0, \quad \text { and } \phi\left(x_{n+1}, z_{n}\right) \rightarrow 0, \quad \text { as } n \rightarrow \infty
$$

Since $\lim _{n \rightarrow \infty} x_{n}=p^{*}$, by virtue of Lemma 2.4 , we get

$$
\lim _{n \rightarrow \infty} y_{n}=p^{*}, \text { and } \lim _{n \rightarrow \infty} z_{n}=p^{*}
$$

It follows from (3.9) and (3.14) that

$$
\lim _{n \rightarrow \infty}\left\|x_{n}-y_{n}\right\|=0, \quad \text { and } \quad \lim _{n \rightarrow \infty}\left\|x_{n}-z_{n}\right\|=0 .
$$

Since $J$ is uniformly continuous on each bounded subset of $E$, then

$$
\lim _{n \rightarrow \infty}\left\|J x_{n}-J y_{n}\right\|=0, \quad \text { and } \quad \lim _{n \rightarrow \infty}\left\|J x_{n}-J z_{n}\right\|=0 .
$$

Step 6. We will show that $p^{*} \in \Omega$, where $\Omega:=\left(\bigcap_{i=1}^{\infty} \operatorname{Fix}\left(T_{i}\right)\right) \cap\left(\bigcap_{i=1}^{\infty} \operatorname{Fix}\left(S_{i}\right)\right)$. (6.1) First, we will show that $p^{*} \in \bigcap_{i=1}^{\infty} \operatorname{Fix}\left(T_{i}\right)$. 
For any $i \geq 1$ and for any $p \in \Omega$, it follows from (3.3), (3.7), (3.15), and (3.16) that

$$
\begin{aligned}
\beta_{n, 0} \beta_{n, i} g\left(\left\|J x_{n}-J T_{i}^{n} x_{n}\right\|\right) & \leq \phi\left(p, x_{n}\right)-\phi\left(p, y_{n}\right)+\xi_{n} \\
& =\left\|x_{n}\right\|^{2}-\left\|y_{n}\right\|^{2}-2\left\langle p, J x_{n}-J y_{n}\right\rangle+\xi_{n} \\
& =\left(\left\|x_{n}\right\|+\left\|y_{n}\right\|\right)\left(\left\|x_{n}\right\|-\left\|y_{n}\right\|\right)-2\left\langle p, J x_{n}-J y_{n}\right\rangle+\xi_{n} \\
& \leq\left(\left\|x_{n}\right\|+\left\|y_{n}\right\|\right)\left(\left\|x_{n}-y_{n}\right\|\right)-2\|p\|\left\|J x_{n}-J y_{n}\right\|+\xi_{n} \\
& \rightarrow 0, \quad \text { as } n \rightarrow \infty .
\end{aligned}
$$

By the condition $\liminf _{n \rightarrow \infty} \beta_{n, 0} \beta_{n, i}>0, \forall i \geq 1$, we obtain

$$
g\left(\left\|J x_{n}-J T_{i}^{n} x_{n}\right\|\right) \rightarrow 0, \quad \text { as } n \rightarrow \infty
$$

It follows from the property of $g$ that

$$
\left\|J x_{n}-J T_{i}^{n} x_{n}\right\| \rightarrow 0, \quad \text { as } n \rightarrow \infty
$$

Since $x_{n} \rightarrow p^{*}$ and $J$ is uniformly continuous on each bounded subset of $E$, it yields that $J x_{n} \rightarrow J p *$

Hence, from (3.17) we get

$$
J T_{i}^{n} x_{n} \rightarrow J p^{*}, \quad \text { as } n \rightarrow \infty, \forall i \geq 1
$$

Since $J^{-1}: E^{*} \rightarrow E$ is norm-to-weak"-continuous, we also have

$$
T_{i}^{n} x_{n} \rightarrow p^{*}, \quad \text { as } n \rightarrow \infty, \forall i \geq 1
$$

Again, since for any $i \geq 1$,

$$
\left|\left\|T_{i}^{n} x_{n}\right\|-\left\|p^{* *}\right\|\right|=\left|\left\|J\left(T_{i}^{n} x_{n}\right)\right\|-\left\|J p^{*}\right\|\right| \leq\left\|J\left(T_{i}^{n} x_{n}\right)-J p^{*}\right\| \rightarrow 0, \quad \text { as } n \rightarrow \infty
$$

from (3.19) and the Kadec-Klee property of $E$, it follows that

$$
\lim _{n \rightarrow \infty} T_{i}^{n} x_{n}=p^{*}
$$

On the other hand, by the assumption that for each $i \geq 1, T_{i}$ is uniformly $L_{i}$-Lipschitz continuous, we get

$$
\begin{aligned}
\left\|T_{i}^{n+1} x_{n}-T_{i}^{n} x_{n}\right\| \leq & \left\|T_{i}^{n+1} x_{n}-T_{i}^{n+1} x_{n+1}\right\|+\left\|T_{i}^{n+1} x_{n+1}-x_{n+1}\right\| \\
& +\left\|x_{n+1}-x_{n}\right\|+\left\|x_{n}-T_{i}^{n} x_{n}\right\| \\
\leq & \left(L_{i}+1\right)\left\|x_{n+1}-x_{n}\right\|+\left\|T_{i}^{n+1} x_{n+1}-x_{n+1}\right\|+\left\|x_{n}-T_{i}^{n} x_{n}\right\| .
\end{aligned}
$$

It follows from (3.9), (3.11), and (3.20) that

$$
\lim _{n \rightarrow \infty}\left\|T_{i}^{n+1} x_{n}-T_{i}^{n} x_{n}\right\|=0, \quad \text { and } \quad \lim _{n \rightarrow \infty} T_{i}^{n+1} x_{n}=p^{*}
$$


and so

$$
\lim _{n \rightarrow \infty} T_{i}^{n+1} x_{n}=\lim _{n \rightarrow \infty} T_{i} T_{i}^{n} x_{n}=\lim _{n \rightarrow \infty} T_{i} p^{*}=p^{*} .
$$

In view of (3.20) and the closeness of $T_{i}$, it yields that $T_{i} p^{*}=p^{*}$ for all $i \geq 1$. This implies that

$$
p^{*} \in \bigcap_{i=1}^{\infty} \operatorname{Fix}\left(T_{i}\right)
$$

(6.2) Next, we will show that $p^{*} \in \bigcap_{i=1}^{\infty} \operatorname{Fix}\left(S_{i}\right)$.

For any $i \geq 1$ and for any $p \in \Omega$, it follows from (3.5), (3.8), (3.15), and (3.16) that

$$
\begin{aligned}
\alpha_{n, 0} \alpha_{n, i} g\left(\left\|J y_{n}-J S_{i}^{n} y_{n}\right\|\right) & \leq \phi\left(p, x_{n}\right)-\phi\left(p, z_{n}\right)+\theta_{n} \\
& =\left\|x_{n}\right\|^{2}-\left\|z_{n}\right\|^{2}-2\left\langle p, J x_{n}-J z_{n}\right\rangle+\theta_{n} \\
& =\left(\left\|x_{n}\right\|+\left\|z_{n}\right\|\right)\left(\left\|x_{n}\right\|-\left\|z_{n}\right\|\right)-2\left\langle p, J x_{n}-J z_{n}\right\rangle+\theta_{n} \\
& \leq\left(\left\|x_{n}\right\|+\left\|z_{n}\right\|\right)\left(\left\|x_{n}-z_{n}\right\|\right)-2\|p\|\left\|J x_{n}-J z_{n}\right\|+\theta_{n} \\
& \rightarrow 0, \quad \text { as } n \rightarrow \infty .
\end{aligned}
$$

By the condition $\liminf _{n \rightarrow \infty} \alpha_{n, 0} \alpha_{n, i}>0, \forall i \geq 1$, we obtain

$$
g\left(\left\|J y_{n}-J S_{i}^{n} y_{n}\right\|\right) \rightarrow 0, \quad \text { as } n \rightarrow \infty .
$$

It follows from the property of $g$ that

$$
\left\|J y_{n}-J S_{i}^{n} y_{n}\right\| \rightarrow 0, \quad \text { as } n \rightarrow \infty .
$$

Since $y_{n} \rightarrow p^{*}$ and $J$ is uniformly continuous on each bounded subset of $E$, it yields that $J y_{n} \rightarrow J p^{*}$.

Hence, from (3.22) we have

$$
J S_{i}^{n} y_{n} \rightarrow J p^{*}, \quad \text { as } n \rightarrow \infty, \forall i \geq 1 .
$$

Since $J^{-1}: E^{*} \rightarrow E$ is norm-to-weak $k^{*}$-continuous, we also have

$$
S_{i}^{n} y_{n} \rightarrow p^{*} \quad \text { as } n \rightarrow \infty, \forall i \geq 1 .
$$

Again, since for any $i \geq 1$,

$$
\left|\left\|S_{i}^{n} y_{n}\right\|-\left\|p^{*}\right\|\right|=\left|\left\|J\left(S_{i}^{n} y_{n}\right)\right\|-\left\|J p^{*}\right\|\right| \leq\left\|J\left(S_{i}^{n} y_{n}\right)-J p^{*}\right\| \rightarrow 0, \quad \text { as } n \rightarrow \infty,
$$

from (3.24) and the Kadec-Klee property of $E$, it follows that

$$
\lim _{n \rightarrow \infty} S_{i}^{n} y_{n}=p^{*} .
$$


On the other hand, by the assumption that for each $i \geq 1, S_{i}$ is uniformly $\ell_{i}$-Lipschitz continuous, we have

$$
\begin{aligned}
\left\|S_{i}^{n+1} y_{n}-S_{i}^{n} y_{n}\right\| \leq & \left\|S_{i}^{n+1} y_{n}-S_{i}^{n+1} y_{n+1}\right\|+\left\|S_{i}^{n+1} y_{n+1}-x_{n+1}\right\|+\left\|x_{n+1}-x_{n}\right\| \\
& +\left\|x_{n}-y_{n}\right\|+\left\|y_{n}-S_{i}^{n} y_{n}\right\| \\
\leq & \ell_{i}\left\|y_{n}-y_{n+1}\right\|+\left\|S_{i}^{n+1} y_{n+1}-x_{n+1}\right\|+\left\|x_{n+1}-x_{n}\right\| \\
& +\left\|x_{n}-y_{n}\right\|+\left\|y_{n}-S_{i}^{n} y_{n}\right\| .
\end{aligned}
$$

From $x_{n} \rightarrow p^{*}, y_{n} \rightarrow p^{*}$ and $S_{i}^{n} y_{n} \rightarrow p^{*}$, as $n \rightarrow \infty$, we obtain

$$
\left\|y_{n}-y_{n+1}\right\| \rightarrow 0, \quad\left\|S_{i}^{n+1} y_{n+1}-x_{n+1}\right\| \rightarrow 0, \quad \text { and } \quad\left\|y_{n}-S_{i}^{n} y_{n}\right\| \rightarrow 0, \quad \text { as } n \rightarrow \infty .
$$

And it follows from (3.11) and (3.15) that

$$
\lim _{n \rightarrow \infty}\left\|S_{i}^{n+1} y_{n}-S_{i}^{n} y_{n}\right\|=0, \quad \text { and } \quad \lim _{n \rightarrow \infty} S_{i}^{n+1} y_{n}=p^{*},
$$

and so

$$
\lim _{n \rightarrow \infty} S_{i}^{n+1} y_{n}=\lim _{n \rightarrow \infty} S_{i} S_{i}^{n} y_{n}=\lim _{n \rightarrow \infty} S_{i} p^{*}=p^{*}
$$

In view of (3.25) and the closeness of $S_{i}$, it yields that $S_{i} p^{*}=p^{*}$ for all $i \geq 1$. This implies that

$$
p^{*} \in \bigcap_{i=1}^{\infty} \operatorname{Fix}\left(S_{i}\right) .
$$

From (3.21) and (3.26), we can conclude that $p^{*} \in \Omega:=\left(\bigcap_{i=1}^{\infty} \operatorname{Fix}\left(T_{i}\right)\right) \cap\left(\bigcap_{i=1}^{\infty} \operatorname{Fix}\left(S_{i}\right)\right)$.

Step 7. Finally, we will show that $x_{n} \rightarrow p^{*}=\Pi_{\Omega}\left(x_{0}\right)$.

Let $w=\Pi_{\Omega}\left(x_{0}\right)$. Since $w \in \Omega \subset C_{n}$ and $x_{n}=\Pi_{C_{n}}\left(x_{0}\right)$, we have

$$
\phi\left(x_{n}, x_{0}\right) \leq \phi\left(w, x_{0}\right), \quad \forall n \geq 0 .
$$

This implies that

$$
\phi\left(p^{*}, x_{0}\right)=\lim _{n \rightarrow \infty} \phi\left(x_{n}, x_{0}\right) \leq \phi\left(w, x_{0}\right) .
$$

In view of the definition of $\Pi_{\Omega}\left(x_{0}\right)$, from (3.27), we have $p^{*}=w$. Therefore, $x_{n} \rightarrow p^{*}=$ $\Pi_{\Omega}\left(x_{0}\right)$.

This completes the proof of Theorem 3.1.

Theorem 3.2 Let E be a uniformly smooth and strictly convex real Banach space with the Kadec-Klee property, and let $C$ be a nonempty, closed, and convex subset of E. We assume the following:

(B1) Let $\left\{T_{i}\right\}_{i=1}^{\infty}: C \rightarrow C$ be a countable family of closed, uniformly $L_{i}$-Lipschitz continuous, and uniformly quasi- $\phi$-asymptotically nonexpansive mappings with a real sequence $\left\{k_{n}\right\} \subset[1, \infty), k_{n} \rightarrow 1$. 
(B2) Let $\left\{S_{i}\right\}_{i=1}^{\infty}: C \rightarrow C$ be a countable family of closed, uniformly $\ell_{i}$-Lipschitz continuous, and uniformly quasi- $\phi$-asymptotically nonexpansive mappings with a real sequence $\left\{l_{n}\right\} \subset[1, \infty), l_{n} \rightarrow 1$.

Suppose that $\Omega:=\left(\bigcap_{i=1}^{\infty} \operatorname{Fix}\left(T_{i}\right)\right) \cap\left(\bigcap_{i=1}^{\infty} \operatorname{Fix}\left(S_{i}\right)\right)$ is a nonempty and bounded in $C$. Let $\left\{x_{n}\right\}_{n=1}^{\infty},\left\{y_{n}\right\}_{n=1}^{\infty}$, and $\left\{z_{n}\right\}_{n=1}^{\infty}$ be sequences generated by

$$
\left\{\begin{array}{l}
x_{0} \in C \quad \text { chosen arbitrarily, } C_{0}=C, \\
z_{n}=J^{-1}\left(\alpha_{n, 0} J x_{n}+\sum_{i=1}^{\infty} \alpha_{n, i} J S_{i}^{n} y_{n}\right), \\
y_{n}=J^{-1}\left(\beta_{n, 0} J x_{n}+\sum_{i=1}^{\infty} \beta_{n, i} J T_{i}^{n} x_{n}\right), \\
C_{n+1}=\left\{v \in C_{n}: \phi\left(v, y_{n}\right) \leq \phi\left(v, x_{n}\right)+\xi_{n} \text { and } \phi\left(v, z_{n}\right) \leq \phi\left(v, x_{n}\right)+\theta_{n}\right\}, \\
x_{n+1}=\Pi_{C_{n+1}}\left(x_{0}\right), \quad \forall n \geq 0,
\end{array}\right.
$$

where $\xi_{n}=\sup _{p \in \Omega}\left(k_{n}-1\right)\left(\phi\left(p, x_{n}\right)\right)$ and $\theta_{n}=\sup _{p \in \Omega}\left(l_{n}-1\right)\left(\phi\left(p, x_{n}\right)\right)$.

Let $\left\{\alpha_{n, i}\right\}$ and $\left\{\beta_{n, i}\right\}$ be coefficient sequences in $[0,1]$ satisfying the following conditions:

(1) $\sum_{i=0}^{\infty} \alpha_{n, i}=1$ and $\sum_{i=0}^{\infty} \beta_{n, i}=1$;

(2) $\liminf _{n \rightarrow \infty} \alpha_{n, 0} \alpha_{n, i}>0$ and $\liminf _{n \rightarrow \infty} \beta_{n, 0} \beta_{n, i}>0, \forall i \geq 1$.

Then the sequence $\left\{x_{n}\right\}_{n=1}^{\infty}$ converges strongly to some point $p^{*}$, where $p^{*}=\Pi_{\Omega}\left(x_{0}\right)$.

Proof Since $\left\{T_{i}\right\}_{i=1}^{\infty},\left\{S_{i}\right\}_{i=1}^{\infty}$ are countable families of closed and uniformly quasi- $\phi$ asymptotically nonexpansive mappings, by virtue of Remark 1.7(2), $\left\{T_{i}\right\}_{i=1}^{\infty},\left\{S_{i}\right\}_{i=1}^{\infty}$ are countable families of closed and uniformly total quasi- $\phi$-asymptotically nonexpansive mappings with nonnegative sequences $v_{n}=k_{n}-1, \mu_{n}=0$, and $\kappa_{n}=l_{n}-1, \omega_{n}=0$, respectively, and a strictly increasing and continuous function $\zeta(t)=\rho(t)=t, t \geq 0$. Hence, $\xi_{n}=\sup _{p \in \Omega}\left(k_{n}-1\right)\left(\phi\left(p, x_{n}\right)\right) \rightarrow 0$ and $\theta_{n}=\sup _{p \in \Omega}\left(l_{n}-1\right)\left(\phi\left(p, x_{n}\right)\right) \rightarrow 0($ as $n \rightarrow \infty)$. Therefore, all the conditions in Theorem 3.1 are satisfied. The conclusion of Theorem 3.2 can be obtained from Theorem 3.1 immediately.

Theorem 3.3 Let E be a uniformly smooth and strictly convex real Banach space with the Kadec-Klee property, and let $C$ be a nonempty, closed, and convex subset of $E$. We assume the following:

(C1) Let $\left\{T_{i}\right\}_{i=1}^{\infty}: C \rightarrow C$ be a countable family of closed and quasi- $\phi$-nonexpansive mappings.

(C2) Let $\left\{S_{i}\right\}_{i=1}^{\infty}: C \rightarrow C$ be a countable family of closed and quasi- $\phi$-nonexpansive mappings.

Suppose that $\Omega:=\left(\bigcap_{i=1}^{\infty} \operatorname{Fix}\left(T_{i}\right)\right) \cap\left(\bigcap_{i=1}^{\infty} \operatorname{Fix}\left(S_{i}\right)\right)$ is nonempty and bounded in $C$. Let $\left\{x_{n}\right\}_{n=1}^{\infty},\left\{y_{n}\right\}_{n=1}^{\infty}$, and $\left\{z_{n}\right\}_{n=1}^{\infty}$ be sequences generated by

$$
\left\{\begin{array}{l}
x_{0} \in C \quad \text { chosen arbitrarily, } C_{0}=C, \\
z_{n}=J^{-1}\left(\alpha_{n, 0} J x_{n}+\sum_{i=1}^{\infty} \alpha_{n, i} J S_{i} y_{n}\right), \\
y_{n}=J^{-1}\left(\beta_{n, 0} J x_{n}+\sum_{i=1}^{\infty} \beta_{n, i} J T_{i} x_{n}\right), \\
C_{n+1}=\left\{v \in C_{n}: \phi\left(v, y_{n}\right) \leq \phi\left(v, x_{n}\right) \text { and } \phi\left(v, z_{n}\right) \leq \phi\left(v, x_{n}\right)\right\}, \\
x_{n+1}=\Pi_{C_{n+1}}\left(x_{0}\right), \quad \forall n \geq 0,
\end{array}\right.
$$

and let $\left\{\alpha_{n, i}\right\}$ and $\left\{\beta_{n, i}\right\}$ be coefficient sequences in $[0,1]$ satisfying the following conditions:

(1) $\sum_{i=0}^{\infty} \alpha_{n, i}=1$, and $\sum_{i=0}^{\infty} \beta_{n, i}=1$; 
(2) $\liminf _{n \rightarrow \infty} \alpha_{n, 0} \alpha_{n, i}>0$, and $\liminf _{n \rightarrow \infty} \beta_{n, 0} \beta_{n, i}>0, \forall i \geq 1$.

Then the sequence $\left\{x_{n}\right\}_{n=1}^{\infty}$ converges strongly to some point $p^{*}$, where $p^{*}=\Pi_{\Omega}\left(x_{0}\right)$.

Proof Since $\left\{T_{i}\right\}_{i=1}^{\infty},\left\{S_{i}\right\}_{i=1}^{\infty}$ are countable families of closed and quasi- $\phi$-nonexpansive mappings, by Remark 1.7(3), $\left\{T_{i}\right\}_{i=1}^{\infty},\left\{S_{i}\right\}_{i=1}^{\infty}$ are countable families of closed and quasi$\phi$-asymptotically nonexpansive mappings with nonnegative sequences $k_{n}=1$ and $l_{n}=1$, respectively. Hence, $\xi_{n}=\sup _{p \in \Omega}\left(k_{n}-1\right)\left(\phi\left(p, x_{n}\right)\right)=0$ and $\theta_{n}=\sup _{p \in \Omega}\left(l_{n}-1\right)\left(\phi\left(p, x_{n}\right)\right)=0$. Therefore, all the conditions in Theorem 3.2 as ' $\Omega$ is bounded in $C$ ' and 'for each $i \geq 1$, $\left\{T_{i}\right\}_{i=1}^{\infty},\left\{S_{i}\right\}_{i=1}^{\infty}$ are uniformly $L_{i}, \ell_{i}$-Lipschitz continuous' are of no use here. Thus, all the conditions in Theorem 3.2 are satisfied. The conclusion of Theorem 3.3 can be obtained from Theorem 3.2 immediately.

Theorem 3.4 Let E be a uniformly smooth and strictly convex real Banach space with the Kadec-Klee property, and let $C$ be a nonempty, closed, and convex subset of $E$. We assume the following:

(D1) Let $\left\{T_{i}\right\}_{i=1}^{\infty}: C \rightarrow C$ be a countable family of weak relatively nonexpansive mappings.

(D2) Let $\left\{S_{i}\right\}_{i=1}^{\infty}: C \rightarrow C$ be a countable family of weak relatively nonexpansive mappings. Suppose that $\Omega:=\left(\bigcap_{i=1}^{\infty} \operatorname{Fix}\left(T_{i}\right)\right) \cap\left(\bigcap_{i=1}^{\infty} \operatorname{Fix}\left(S_{i}\right)\right)$ is nonempty and bounded in $C$. Let $\left\{x_{n}\right\}_{n=1}^{\infty},\left\{y_{n}\right\}_{n=1}^{\infty}$, and $\left\{z_{n}\right\}_{n=1}^{\infty}$ be sequences generated by

$$
\left\{\begin{array}{l}
x_{0} \in C \quad \text { chosen arbitrarily, } C_{0}=C, \\
z_{n}=J^{-1}\left(\alpha_{n, 0} J x_{n}+\sum_{i=1}^{\infty} \alpha_{n, i} J S_{i} y_{n}\right), \\
y_{n}=J^{-1}\left(\beta_{n, 0} J x_{n}+\sum_{i=1}^{\infty} \beta_{n, i} J T_{i} x_{n}\right), \\
C_{n+1}=\left\{v \in C_{n}: \phi\left(v, y_{n}\right) \leq \phi\left(v, x_{n}\right) \text { and } \phi\left(v, z_{n}\right) \leq \phi\left(v, x_{n}\right)\right\}, \\
x_{n+1}=\Pi_{C_{n+1}}\left(x_{0}\right), \quad \forall n \geq 0,
\end{array}\right.
$$

and let $\left\{\alpha_{n, i}\right\}$ and $\left\{\beta_{n, i}\right\}$ be coefficient sequences in $[0,1]$ satisfying the following conditions:

(1) $\sum_{i=0}^{\infty} \alpha_{n, i}=1$ and $\sum_{i=0}^{\infty} \beta_{n, i}=1$;

(2) $\liminf _{n \rightarrow \infty} \alpha_{n, 0} \alpha_{n, i}>0$ and $\liminf _{n \rightarrow \infty} \beta_{n, 0} \beta_{n, i}>0, \forall i \geq 1$.

Then the sequence $\left\{x_{n}\right\}_{n=1}^{\infty}$ converges strongly to some point $p^{*}$, where $p^{*}=\Pi_{\Omega}\left(x_{0}\right)$.

Proof Since $\left\{T_{i}\right\}_{i=1}^{\infty},\left\{S_{i}\right\}_{i=1}^{\infty}$ are countable families of weak relatively nonexpansive mappings, from Remark 1.7(4), $\left\{T_{i}\right\}_{i=1}^{\infty},\left\{S_{i}\right\}_{i=1}^{\infty}$ are countable families of quasi- $\phi$-nonexpansive mappings. Therefore, all the conditions in Theorem 3.3 are satisfied. The conclusion of Theorem 3.4 can be obtained from Theorem 3.3 immediately.

Theorem 3.5 Let E be a uniformly smooth and strictly convex real Banach space with the Kadec-Klee property, and let $C$ be a nonempty, closed, and convex subset of $E$. We assume the following:

(E1) Let $\left\{T_{i}\right\}_{i=1}^{\infty}: C \rightarrow C$ be a countable family of relatively nonexpansive mappings.

(E2) Let $\left\{S_{i}\right\}_{i=1}^{\infty}: C \rightarrow C$ be a countable family of relatively nonexpansive mappings. 
Suppose that $\Omega:=\left(\bigcap_{i=1}^{\infty} \operatorname{Fix}\left(T_{i}\right)\right) \cap\left(\bigcap_{i=1}^{\infty} \operatorname{Fix}\left(S_{i}\right)\right)$ is nonempty and bounded in $C$. Let $\left\{x_{n}\right\}_{n=1}^{\infty},\left\{y_{n}\right\}_{n=1}^{\infty}$, and $\left\{z_{n}\right\}_{n=1}^{\infty}$ be sequences generated by

$$
\left\{\begin{array}{l}
x_{0} \in C \quad \text { chosen arbitrarily, } C_{0}=C, \\
z_{n}=J^{-1}\left(\alpha_{n, 0} J x_{n}+\sum_{i=1}^{\infty} \alpha_{n, i} J S_{i} y_{n}\right), \\
y_{n}=J^{-1}\left(\beta_{n, 0} J x_{n}+\sum_{i=1}^{\infty} \beta_{n, i} J T_{i} x_{n}\right), \\
C_{n+1}=\left\{v \in C_{n}: \phi\left(v, y_{n}\right) \leq \phi\left(v, x_{n}\right) \text { and } \phi\left(v, z_{n}\right) \leq \phi\left(v, x_{n}\right)\right\}, \\
x_{n+1}=\Pi_{C_{n+1}}\left(x_{0}\right), \quad \forall n \geq 0,
\end{array}\right.
$$

and let $\left\{\alpha_{n, i}\right\}$ and $\left\{\beta_{n, i}\right\}$ be coefficient sequences in $[0,1]$ satisfying the following conditions:

(1) $\sum_{i=0}^{\infty} \alpha_{n, i}=1$ and $\sum_{i=0}^{\infty} \beta_{n, i}=1$;

(2) $\liminf _{n \rightarrow \infty} \alpha_{n, 0} \alpha_{n, i}>0$ and $\liminf _{n \rightarrow \infty} \beta_{n, 0} \beta_{n, i}>0, \forall i \geq 1$.

Then the sequence $\left\{x_{n}\right\}_{n=1}^{\infty}$ converges strongly to some point $p^{*}$, where $p^{*}=\Pi_{\Omega}\left(x_{0}\right)$.

Proof Since $\left\{T_{i}\right\}_{i=1}^{\infty},\left\{S_{i}\right\}_{i=1}^{\infty}$ are countable families of relatively nonexpansive mappings, it follows from Remark 1.7(5) that $\left\{T_{i}\right\}_{i=1}^{\infty},\left\{S_{i}\right\}_{i=1}^{\infty}$ are countable families of weak relatively nonexpansive mappings. Therefore, all the conditions in Theorem 3.4 are satisfied. The conclusion of Theorem 3.5 can be obtained from Theorem 3.4 immediately.

Remark 3.6 Theorems 3.1-3.5 generalize, improve, and extend the corresponding results in $[5-8,11-18]$, and [19] in the following aspects:

(a) For the framework of spaces, we extend the space from a uniformly smooth and uniformly convex Banach space to a uniformly smooth and strictly convex real Banach space with the Kadec-Klee property. (Note that each uniformly convex Banach space must have the Kadec-Klee property.)

(b) For the mappings, we extend the mappings from a nonexpansive mapping, a relatively nonexpansive mapping, a weakly relatively nonexpansive mapping, a quasi- $\phi$ nonexpansive mapping or a quasi- $\phi$-asymptotically nonexpansive mapping to a total quasi- $\phi$-asymptotically nonexpansive mapping.

(c) We extend a countable family of closed and uniformly $L_{i}$-Lipschitz continuous and uniformly total quasi- $\phi$-asymptotically nonexpansive mappings to two countable families of closed and uniformly $L_{i}$-Lipschitz continuous and uniformly total quasi- $\phi$ asymptotically nonexpansive mappings.

\section{Deduced theorem}

If we take $i=1$ in Theorem 3.1, then we obtain the following result.

Theorem 4.1 Let E be a uniformly smooth and strictly convex real Banach space with the Kadec-Klee property, and let $C$ be a nonempty, closed, and convex subset of E. We assume the following:

(F1) Let $T: C \rightarrow C$ be a closed, uniformly L-Lipschitz continuous, and uniformly total quasi- $\phi$-asymptotically nonexpansive mapping with nonnegative real sequences $\left\{v_{n}\right\},\left\{\mu_{n}\right\}$, and a strictly increasing function $\zeta: \mathbb{R}^{+} \rightarrow \mathbb{R}^{+}$such that $v_{n} \rightarrow 0, \mu_{n} \rightarrow 0($ as $n \rightarrow \infty)$, $\zeta(0)=0$, and

$$
\phi\left(p, T^{n} x\right) \leq \phi(p, x)+v_{n} \zeta(\phi(p, x))+\mu_{n}, \quad \forall x \in C, p \in \operatorname{Fix}(T), \text { and } \forall n \geq 1
$$


(F2) Let $S: C \rightarrow C$ be a closed, uniformly $\ell$-Lipschitz continuous, and uniformly total quasi- $\phi$-asymptotically nonexpansive mapping with nonnegative real sequences $\left\{\kappa_{n}\right\},\left\{\omega_{n}\right\}$, and a strictly increasing function $\rho: \mathbb{R}^{+} \rightarrow \mathbb{R}^{+}$such that $\kappa_{n} \rightarrow 0, \omega_{n} \rightarrow 0($ as $n \rightarrow \infty)$, $\rho(0)=0$, and

$$
\phi\left(p, S^{n} x\right) \leq \phi(p, x)+\kappa_{n} \rho(\phi(p, x))+\omega_{n}, \quad \forall x \in C, p \in \operatorname{Fix}(S), \text { and } \forall n \geq 1 .
$$

Suppose that $\Omega:=\operatorname{Fix}(T) \cap \operatorname{Fix}(S)$ is nonempty and bounded in C. Let $\left\{x_{n}\right\}_{n=1}^{\infty},\left\{y_{n}\right\}_{n=1}^{\infty}$, and $\left\{z_{n}\right\}_{n=1}^{\infty}$ be sequences generated by

$$
\left\{\begin{array}{l}
x_{0} \in C \quad \text { chosen arbitrarily, } C_{0}=C, \\
z_{n}=J^{-1}\left(\alpha_{n} J x_{n}+\left(1-\alpha_{n}\right) J S^{n} y_{n}\right), \\
y_{n}=J^{-1}\left(\beta_{n} J x_{n}+\left(1-\beta_{n}\right) J T^{n} x_{n}\right), \\
C_{n+1}=\left\{v \in C_{n}: \phi\left(v, y_{n}\right) \leq \phi\left(v, x_{n}\right)+\xi_{n} \text { and } \phi\left(v, z_{n}\right) \leq \phi\left(v, x_{n}\right)+\theta_{n}\right\}, \\
x_{n+1}=\Pi_{C_{n+1}}\left(x_{0}\right), \quad \forall n \geq 0,
\end{array}\right.
$$

where $\xi_{n}=v_{n} \sup _{p \in \Omega} \zeta\left(\phi\left(p, x_{n}\right)\right)+\mu_{n}$ and $\theta_{n}=\kappa_{n} \sup _{p \in \Omega} \rho\left(\phi\left(p, x_{n}\right)\right)+\omega_{n}$.

Let $\left\{\alpha_{n}\right\}$ and $\left\{\beta_{n}\right\}$ be coefficient sequences in $[0,1]$ satisfying the following conditions:

(1) $0 \leq \alpha_{n} \leq \alpha<1$ for some $\alpha \in(0,1)$;

(2) $0 \leq \beta_{n} \leq \beta<1$ for some $\beta \in(0,1)$.

Then the sequence $\left\{x_{n}\right\}_{n=1}^{\infty}$ converges strongly to some point $p^{*}$, where $p^{*}=\Pi_{\Omega}\left(x_{0}\right)$.

If we set $S_{i}^{n}=I$ (identity mapping) for all $i=1,2,3, \ldots$ in Theorem 3.1 , then we obtain the following result.

Theorem 4.2 Let E be a uniformly smooth and strictly convex real Banach space with the Kadec-Klee property, and let $C$ be a nonempty, closed, and convex subset of $E$. We assume the following:

(G1) Let $\left\{T_{i}\right\}_{i=1}^{\infty}: C \rightarrow C$ be a countable family of closed, uniformly $L_{i}$-Lipschitz continuous, and uniformly total quasi- $\phi$-asymptotically nonexpansive mappings with nonnegative real sequences $\left\{v_{n}\right\},\left\{\mu_{n}\right\}$, and a strictly increasing function $\zeta: \mathbb{R}^{+} \rightarrow \mathbb{R}^{+}$such that $v_{n} \rightarrow 0$, $\mu_{n} \rightarrow 0($ as $n \rightarrow \infty), \mu_{1}=0$, and $\zeta(0)=0$, and for each $i \geq 1$,

$$
\phi\left(p, T_{i}^{n} x\right) \leq \phi(p, x)+v_{n} \zeta(\phi(p, x))+\mu_{n}, \quad \forall x \in C, p \in \bigcap_{i=1}^{\infty} \operatorname{Fix}\left(T_{i}\right), \text { and } \forall n \geq 1 .
$$

(G2) Suppose that $\Omega:=\bigcap_{i=1}^{\infty} \operatorname{Fix}\left(T_{i}\right)$ is nonempty and bounded in C. Let $\left\{x_{n}\right\}_{n=1}^{\infty},\left\{y_{n}\right\}_{n=1}^{\infty}$, and $\left\{z_{n}\right\}_{n=1}^{\infty}$ be sequences generated by

$$
\left\{\begin{array}{l}
x_{0} \in C \quad \text { chosen arbitrarily, } C_{0}=C \\
z_{n}=J^{-1}\left(\alpha_{n} J x_{n}+\left(1-\alpha_{n}\right) J y_{n}\right) \\
y_{n}=J^{-1}\left(\beta_{n, 0} J x_{n}+\sum_{i=1}^{\infty} \beta_{n, i} J T_{i}^{n} x_{n}\right) \\
C_{n+1}=\left\{v \in C_{n}: \phi\left(v, y_{n}\right) \leq \phi\left(v, x_{n}\right)+\xi_{n}\right\} \\
x_{n+1}=\Pi_{C_{n+1}}\left(x_{0}\right), \quad \forall n \geq 0
\end{array}\right.
$$


where $\xi_{n}=v_{n} \sup _{p \in \Omega} \zeta\left(\phi\left(p, x_{n}\right)\right)+\mu_{n}$. Let $\left\{\alpha_{n}\right\}$ and $\left\{\beta_{n, i}\right\}$ be coefficient sequences in $[0,1]$ satisfying the following conditions:

(1) $0 \leq \alpha_{n} \leq \alpha<1$ for some $\alpha \in(0,1)$;

(2) $\sum_{i=0}^{\infty} \beta_{n, i}=1$;

(3) $\liminf _{n \rightarrow \infty} \beta_{n, 0} \beta_{n, i}>0, \forall i \geq 1$.

Then the sequence $\left\{x_{n}\right\}_{n=1}^{\infty}$ converges strongly to some point $p^{\prime \prime}$, where $p^{\prime \prime}=\Pi_{\Omega}\left(x_{0}\right)$.

Remark 4.3 Theorem 4.2 contains the result of Chang et al. [8].

\section{Applications}

Now, we apply Theorem 3.5 to prove a strong convergence theorem concerning two maximal monotone operators in Banach spaces.

Let $E$ be a smooth, strictly convex, and reflexive real Banach space, and let $A: E \rightarrow E^{*}$ be a maximal monotone operator. For each $r>0$, we can define a single value mapping $J_{r}: E \rightarrow D(A)$ by $J_{r}=(J+r A)^{-1} J$, and such a mapping $J_{r}$ is called the resolvent of $A$. It is easy to prove that $A^{-1}(0)=F\left(J_{r}\right)$ for all $r>0$. Using Theorem 3.5, we can obtain the following strong convergence theorem for maximal monotone operators.

Theorem 5.1 Let E be a uniformly smooth and strictly convex real Banach space with the Kadec-Klee property, and let $C$ be a nonempty, closed, and convex subset of E. We assume the following:

(H1) Let $A, B$ be two maximal monotone operators from $E$ to $E^{*}$, and let $J_{r}^{A}, J_{r}^{B}$ be the resolvent of $A$ and $B$, respectively, where $r>0$.

(H2) Suppose that $\Omega:=A^{-1}(0) \cap B^{-1}(0)$ is nonempty, and let $\left\{x_{n}\right\}_{n=1}^{\infty},\left\{y_{n}\right\}_{n=1}^{\infty}$, and $\left\{z_{n}\right\}_{n=1}^{\infty}$ be sequences generated by

$$
\left\{\begin{array}{l}
x_{0} \in C \quad \text { chosen arbitrarily, } C_{0}=C \\
z_{n}=J^{-1}\left(\alpha_{n, 0} J x_{n}+\sum_{i=1}^{\infty} \alpha_{n, i} J J_{r_{i}}^{B} y_{n}\right) \\
y_{n}=J^{-1}\left(\beta_{n, 0} J x_{n}+\sum_{i=1}^{\infty} \beta_{n, i} J J_{r_{i}}^{A} x_{n}\right) \\
C_{n+1}=\left\{v \in C_{n}: \phi\left(v, y_{n}\right) \leq \phi\left(v, x_{n}\right) \text { and } \phi\left(v, z_{n}\right) \leq \phi\left(v, x_{n}\right)\right\} \\
x_{n+1}=\Pi_{C_{n+1}}\left(x_{0}\right), \quad \forall n \geq 0,
\end{array}\right.
$$

where $r_{n}>0$ with $\liminf _{n \rightarrow \infty} r_{n}>0$, and let $\left\{\alpha_{n, i}\right\}$ and $\left\{\beta_{n, i}\right\}$ be coefficient sequences in $[0,1]$ satisfying the following conditions:

(1) $\sum_{i=0}^{\infty} \alpha_{n, i}=1$, and $\sum_{i=0}^{\infty} \beta_{n, i}=1$;

(2) $\liminf _{n \rightarrow \infty} \alpha_{n, 0} \alpha_{n, i}>0$, and $\liminf _{n \rightarrow \infty} \beta_{n, 0} \beta_{n, i}>0, \forall i \geq 1$.

Then the sequence $\left\{x_{n}\right\}_{n=1}^{\infty}$ converges strongly to some point $p^{*}$, where $p^{*}=\Pi_{\Omega}\left(x_{0}\right)$.

Proof It is well known that for each $i \geq 1, J_{r_{i}}^{A}$ is a relatively nonexpansive mapping (see, for example, $[5,6,19])$. Therefore, for each $p \in F\left(J_{r_{i}}^{A}\right)$ and $w \in E$, we have

$$
\phi\left(p, J_{r_{i}}^{A} w\right) \leq \phi(p, w)
$$

Again, by the same method, we can prove that the set of strong asymptotically fixed points

$$
\widetilde{F}\left(\left\{J_{r_{i}}^{A}\right\}_{i=1}^{\infty}\right)=\bigcap_{i=1}^{\infty} F\left(J_{r_{i}}^{A}\right)=A^{-1}(0) .
$$


This implies that $\left\{J_{r_{i}}^{A}\right\}_{i=1}^{\infty}$ is a countable family of weak relatively nonexpansive mappings with the common fixed point set $\bigcap_{n=1}^{\infty} F\left(J_{r_{i}}^{A}\right)=A^{-1}(0)$. By a similar way, we can prove that $\left\{J_{r_{i}}^{B}\right\}_{i=1}^{\infty}$ is a countable family of weak relatively nonexpansive mappings with the common fixed point set $\bigcap_{n=1}^{\infty} F\left(J_{r_{i}}^{B}\right)=B^{-1}(0)$. Hence, the conclusion of Theorem 5.1 can be obtained from Theorem 3.5 immediately.

Remark 5.2 Theorem 5.1 improves and extends Theorem 4.1 of Chang et al. [10] from one maximal monotone operator to two maximal monotone operators.

\section{Competing interests}

All authors declare that they have no competing interests.

Authors' contributions

All authors contributed equally and significantly in this research. All authors read and approved the final manuscript.

\section{Author details}

${ }^{1}$ Department of Mathematics, Faculty of Science, King Mongkut's University of Technology Thonburi (KMUTT), Bang Mod, Thung Kru, Bangkok, 10140, Thailand. ²Department of Mathematics, Faculty of Education, Bansomdejchaopraya Rajabhat University (BSRU), Thonburi, Bangkok, 10600, Thailand.

\section{Acknowledgements}

The first author would like to thank the Bansomdejchaopraya Rajabhat University for financial support for the Ph.D. program at King Mongkut's University of Technology Thonburi (KMUTT). The second author would like to thank the Higher Education Research Promotion and National Research University Project of Thailand's Office of the Higher Education Commission for financial support (Under NRU-CSEC Project No.55000613).

Received: 4 May 2012 Accepted: 16 October 2012 Published: 30 October 2012

\section{References}

1. Cioranescu, I: Geometry of Banach spaces, duality mappings and nonlinear problem. In: Hazewinkel, M (ed.) Mathematics and Its Applications, vol. 62. Kluwer Academic, Dordrecht (1990)

2. Takahashi, W: Nonlinear Functional Analysis. Fixed Point Theory and Its Application. Yokohama-Publishers, Yokohama (2000)

3. Alber, Yl: Metric and generalized projection operators in Banach space: properties and applications. In: Kartosator, AG (ed.) Theory and Applications of Nonlinear Operators of Accretive and Monotone Type. Lecture Notes in Pure and Applied Mathematics, vol. 178, pp. 15-50. Dekker, New York (1996)

4. Kamimura, S, Takahashi, W: Strong convergence of a proximal-type algorithm in a Banach space. SIAM J. Optim. 13(3), 938-945 (2002)

5. Matsushita, S, Takahashi, W: A strong convergence theorem for relatively nonexpansive mappings in Banach space. J. Approx. Theory 134, 257-266 (2005)

6. Plubtieng, S, Ungchittrakool, K: Hybrid iterative methods for convex feasibility problems and fixed point problems of relatively nonexpansive mappings in Banach space. Fixed Point Theory Appl. 2008, Article ID 583082 (2008)

7. Su, YF, Xu, HK, Zhang, X: Strong convergence theorems for two countable families of weak relatively nonexpansive mappings and applications. Nonlinear Anal. 73, 3890-3906 (2010)

8. Chang, SS, Lee, HWJ, Chan, CK, Yang, L: Approximation theorems for total quasi- $\phi$-asymptotically nonexpansive mapping with applications. Appl. Math. Comput. 218, 2921-2931 (2011)

9. Chang, SS, Lee, HWJ, Chan, CK, Zhang, WB: A modified Halpern-type iteration algorithm for totally quasi- $\boldsymbol{\phi}$-asymptotically nonexpansive mappings with applications. Appl. Math. Comput. 12(5), 1483-1492 (2012) doi:10.1016/j.amc.2011.12.019

10. Chang, SS, Lee, HWJ, Chan, CK: A block hybrid method for solving generalized equilibrium problems and convex feasibility problem. Adv. Comput. Math. (2011). doi:10.1007/s10444-011-9249-5

11. Chang, SS, Kim, JK, Wang, XR: Modified block iterative algorithm for solving convex feasibility problems in Banach spaces. J. Inequal. Appl. 14, Article ID 869684 (2010)

12. Aleyner, A, Reich, S: Block-iterative algorithm for solving convex feasibility problems in Hilbert and Banach space. J. Math. Anal. Appl. 343(1), 427-435 (2008)

13. Li, HY, Su, YF: Strong convergence theorems by a new hybrid for equilibrium problems and variational inequality problems. Nonlinear Anal. 72(2), 847-855 (2010)

14. Takahashi, W, Zembayashi, K: Strong and weak convergence theorems for equilibrium problems and relatively nonexpansive mappings in Banach spaces. Nonlinear Anal. 70(1), 45-57 (2009)

15. Wang, ZM, Su, YF, Wang, DX, Dong, YC: A modified Halpern-type iteration algorithm for a family of hemi-relative nonexpansive mappings and a system of equilibrium problems in Banach spaces. J. Comput. Appl. Math. 235, 2364-2371 (2011)

16. Chang, SS, Chan, CK, Lee, HWJ: Modified block iterative algorithm for quasi- $\phi$-asymptotically nonexpansive mappings and equilibrium problems in Banach spaces. Appl. Math. Comput. 217, 7520-7530 (2011)

17. Yao, YH, Liou, YC, Kang, SM: Strong convergence of an iterative algorithm on an infinite countable family of nonexpansive mappings. Appl. Math. Comput. 208, 211-218 (2009) 
18. Zegeye, $\mathrm{H}$, Ofoedu, EU, Shahzad, N: Convergence theorems for equilibrium problem, variational inequality problem and countable infinite relatively quasi-nonexpansive mappings. Appl. Math. Comput. 216, 3439-3449 (2010)

19. Wattanawitoon, K, Kumam, P: Strong convergence theorems by a new hybrid projection algorithm for fixed point problem and equilibrium problems of two relatively quasi-nonexpansive mappings. Nonlinear Anal. Hybrid Syst. 3(1), $11-20(2010)$

doi:10.1186/1687-1812-2012-198

Cite this article as: Phuangphoo and Kumam: Modified block iterative procedure for solving the common solution of fixed point problems for two countable families of total quasi- $\phi$-asymptotically nonexpansive mappings with applications. Fixed Point Theory and Applications 2012 2012:198.

Submit your manuscript to a SpringerOpen ${ }^{\odot}$ journal and benefit from:

- Convenient online submission

- Rigorous peer review

- Immediate publication on acceptance

Open access: articles freely available online

- High visibility within the field

- Retaining the copyright to your article 